\title{
Competition between water uptake and ice nucleation by glassy organic aerosol particles
}

\author{
T. Berkemeier ${ }^{1,2}$, M. Shiraiwa ${ }^{1}$, U. Pöschl ${ }^{1}$, and T. Koop ${ }^{2}$ \\ ${ }^{1}$ Multiphase Chemistry Department, Max Planck Institute for Chemistry, Mainz, Germany \\ ${ }^{2}$ Faculty of Chemistry, Bielefeld University, Bielefeld, Germany \\ Correspondence to: T. Berkemeier (t.berkemeier@mpic.de) and T. Koop (thomas.koop@uni-bielefeld.de)
}

Received: 2 June 2014 - Published in Atmos. Chem. Phys. Discuss.: 20 June 2014

Revised: 9 October 2014 - Accepted: 24 October 2014 - Published: 27 November 2014

\begin{abstract}
Organic aerosol particles play a key role in climate by serving as nuclei for clouds and precipitation. Their sources and composition are highly variable, and their phase state ranges from liquid to solid under atmospheric conditions, affecting the pathway of activation to cloud droplets and ice crystals. Due to slow diffusion of water in the particle phase, organic particles may deviate in phase and morphology from their thermodynamic equilibrium state, hampering the prediction of their influence on cloud formation. We overcome this problem by combining a novel semi-empirical method for estimation of water diffusivity with a kinetic flux model that explicitly treats water diffusion. We estimate timescales for particle deliquescence as well as various ice nucleation pathways for a wide variety of organic substances, including secondary organic aerosol (SOA) from the oxidation of isoprene, $\alpha$-pinene, naphthalene, and dodecane. The simulations show that, in typical atmospheric updrafts, glassy states and solid/liquid core-shell morphologies can persist for long enough that heterogeneous ice nucleation in the deposition and immersion mode can dominate over homogeneous ice nucleation. Such competition depends strongly on ambient temperature and relative humidity as well as humidification rate and particle size. Due to differences in glass transition temperature, hygroscopicity and atomic $\mathrm{O} / \mathrm{C}$ ratio of the different SOA, naphthalene SOA particles have the highest potential to act as heterogeneous ice nuclei. Our findings demonstrate that kinetic limitations of water diffusion into organic aerosol particles are likely to be encountered under atmospheric conditions and can strongly affect ice nucleation pathways. For the incorporation of ice nucleation by organic aerosol particles into atmospheric models, our results demonstrate a demand for
\end{abstract}

model formalisms that account for the effects of molecular diffusion and not only describe ice nucleation onsets as a function of temperature and relative humidity but also include updraft velocity, particle size and composition.

\section{Introduction}

Atmospheric aerosol particles influence climate through affecting the earth's radiation budget directly by scattering and absorbing light, and indirectly by acting as nuclei for cloud droplets and ice crystals (Yu et al., 2006; Andreae and Rosenfeld, 2008; IPCC, 2013). Ice nucleation is an important pathway for high-altitude cirrus cloud formation, and it occurs either homogeneously in liquid aerosol particles or heterogeneously in the presence of active ice nuclei (IN), which are solid particles that facilitate nucleation. Homogeneous ice nucleation generally requires high supersaturations in aqueous aerosol droplets, occurring at ice saturation ratios of $S_{\text {ice }} \geq 1.4$ (Koop et al., 2000). Only a small fraction of atmospheric aerosol particles act as IN below this homogeneous ice nucleation threshold (DeMott et al., 2003; Cziczo et al., 2013). Heterogeneous ice nucleation can occur via several pathways such as deposition nucleation, i.e. deposition of gaseous water molecules to form crystalline ice on a solid IN, or immersion freezing, which describes nucleation induced by IN immersed in supercooled aqueous droplets (Pruppacher and Klett, 1997; Hoose and Möhler, 2012).

Organic aerosol particles are ubiquitous and abundant in the atmosphere, but traditionally they are not referred to as effective IN when compared to dust or biological particles (see Hoose and Möhler (2012) and references therein). More 
recently, however, several laboratory studies have shown that glassy organic particles can act as IN at low-temperature cirrus conditions in the deposition mode or at slightly elevated temperatures in the immersion mode (Murray et al., 2010; Wagner et al., 2012; Wang et al., 2012; Wilson et al., 2012; Baustian et al., 2013; Schill et al., 2014), in agreement with inferences from field data (Froyd et al., 2010; Knopf et al., 2010, 2014). This IN ability has been observed for a number of different types of particles composed of pure organic substances such as simple sugars and acids (Murray et al., 2010; Wagner et al., 2012; Wilson et al., 2012; Baustian et al., 2013) and biomass burning marker compounds (Wagner et al., 2012; Wilson et al., 2012), for (phase-separated) organic-inorganic mixtures (Wagner et al., 2012; Wilson et al., 2012; Baustian et al., 2013; Schill and Tolbert, 2013), as well as for secondary organic aerosol (SOA) particles derived from aromatic volatile organic compounds (VOCs, Wang et al., 2012) or emerging from aqueous phase reactions (Schill et al., 2014). It has also been proposed recently that formation of highly porous structures upon atmospheric freezedrying could enhance the IN ability of organic aerosol particles (Adler et al., 2013).

These observations suggest a connection between particle phase state and the resulting predominant ice nucleation pathway (Murray et al., 2010). Organic aerosol particles can adopt liquid, semisolid or solid states, or may even exhibit mixed phases, depending on composition and ambient conditions (Mikhailov et al., 2009; Koop et al., 2011; Vaden et al., 2011; Kuwata and Martin, 2012; Perraud et al., 2012; Song et al., 2012; You et al., 2012; Renbaum-Wolff et al., 2013; Kidd et al., 2014). SOA particles are expected to be liquid at high temperature and high humidity, but they are very likely to exhibit a highly viscous semisolid or even glassy state at low temperature and low humidity (Virtanen et al., 2010; Saukko et al., 2012; Renbaum-Wolff et al., 2013; Shiraiwa et al., 2013a). For example, typical $\alpha$-pinene-derived secondary organic aerosol particles are expected to be in a glassy state below about $260 \mathrm{~K}$ at $30 \%$ relative humidity, whereas at a higher humidity of $80 \%$ such a glass transition is expected at approximately $215 \mathrm{~K}$ (Koop et al., 2011). Glassy states are characterized by viscosities greater than $10^{12} \mathrm{~Pa} \mathrm{~s}$, corresponding to diffusion timescales within these particles that can exceed days or even years (Shiraiwa et al., 2011; Koop et al., 2011; Zhou et al., 2013). Water uptake into glassy aerosols has been shown to occur slowly and to proceed gradually with increasing relative humidity (Mikhailov et al., 2009; Tong et al., 2011; Zobrist et al., 2011; Bones et al., 2012; Price et al., 2014).

Hence, several competing processes can occur in glassy organic aerosol particles during updraft of an air parcel: heterogeneous ice nucleation in the deposition mode onto the glassy solid aerosol surface; diffusion of water into the particle, inducing a gradual phase transition towards the liquid state; and immersion freezing during the transition between both states. In order to determine those atmospheric condi- tions at which each of these processes dominates, we employ a numerical aerosol diffusion model based on the kinetic multi-layer model for gas-particle interactions in aerosols and clouds (KM-GAP), which explicitly treats mass transport of water molecules in the gas and particle phases (Shiraiwa et al., 2012). Due to experimental constraints associated with very long observation times, parameterizations for water diffusivity in glassy organic material are sparse and hence are only known for a few model compounds. Therefore, water diffusivity in SOA materials from various biogenic and anthropogenic precursors are deduced from water diffusivity parameterizations of model compounds using a semi-empirical physico-chemical model of water diffusion in glass-forming aqueous organics.

\section{Modelling approach}

\subsection{Numerical diffusion model}

The numerical diffusion model employed in this study is based on the kinetic multi-layer model for gas-particle interactions in aerosols and clouds, KM-GAP (Shiraiwa et al., 2012). KM-GAP consists of multiple model compartments and layers, respectively: gas phase, near-surface gas phase, sorption layer, surface layer, near-surface bulk, and a number of $n$ bulk layers (cf. Fig. S1). The following processes are considered in KM-GAP: gas-phase diffusion, gassurface transport, surface-bulk transport, and bulk diffusion. The bulk layers can either grow or shrink in response to mass transport. The initial bulk layer sizes are chosen to be small enough to ensure numerical convergence (usually 100-750 layers), but are not allowed to fall below the molecular length scale $(\sim 0.3 \mathrm{~nm})$.

The model was complemented by modules predicting homogeneous ice nucleation as a function of water activity according to Koop et al. (2000), heterogeneous ice nucleation at a pre-defined ice supersaturation level, and it considers Kelvin effects. Moreover, a few further conceptual changes have been introduced to the original KM-GAP, including a more explicit treatment of gas diffusion, composition-based bulk diffusion and a mechanism of surface-to-bulk transport facilitated by surface-adsorbed water, as detailed in the following sections. Parameterizations of compositiondependent density, water activity and bulk diffusivity for the sucrose/water system have been adopted from Zobrist et al. (2011). A detailed description of the gas diffusion scheme and a list of all employed parameterizations are provided as supplementary material.

In this study, the model is used to simulate an atmospheric updraft situation by following a preselected trajectory in temperature and relative humidity. It tracks the chemical composition of an amorphous aerosol particle as a function of time and depth below the particle surface in discretized layers, providing concentration profiles of water and organics 
at any given time. The equilibrium composition is calculated through a water activity parameterization that translates ambient relative humidity into equilibrium mass fractions of the bulk constituents. Mass fluxes from the far-surface into the near-surface gas phase, onto the particle surface, into as well as between bulk layers are coupled in flux-based differential equations, which are solved with an ordinary differential equation solver using Matlab software (ode23tb).

\subsubsection{Ice nucleation modules}

Besides water diffusion, the model is able to simulate ice nucleation and growth. However, the initial numerical solution of the differential equations only treats water uptake into the particle. The model registers an ice nucleation event when all necessary conditions in ambient relative humidity and water activity are satisfied. From this point onwards, the model simulates ice crystal growth by deposition of water molecules from the gas phase.

For homogeneous ice nucleation, a stochastic approach based on classical nucleation theory has been chosen. An ice nucleation event is triggered when the probability of the particle being liquid $\left(P_{\text {liq }}\right.$ ) falls below $50 \%$. $P_{\text {liq }}$ is the product of the individual probabilities in all $n$ layers, using the homogeneous nucleation rate coefficient for each layer $J_{\mathrm{hom}, k}$ as parameterized by Koop et al. (2000). The nucleation rate then translates into $P_{\text {liq }}$ by multiplication with layer volume $V_{k}$ and (numerical) integration with time step $\mathrm{d} t$ :

$P_{\text {liq,tot }}(t)=\int_{t_{0}}^{t} \prod_{k=1}^{n}\left(1-J_{\text {hom }, k}(t) \cdot V_{k}(t)\right) \mathrm{d} t$.

Heterogeneous nucleation is assumed to occur once a certain freezing threshold is exceeded. In this work, we distinguish between heterogeneous ice nucleation thresholds for sucrose and SOA, which have been shown to occur at different ice supersaturations, as summarized by Schill et al. (2014). For sucrose, we apply a linear fit to nucleation data from Baustian et al. (2013), whereas for SOA we fit the nucleation data of naphthalene SOA from Wang et al. (2012) and those of aqueous SOA (aqSOA) from Schill et al. (2014). The fit results are shown in Fig. A1 in Appendix A.

To distinguish between deposition and immersion freezing, additional criteria are employed. For deposition nucleation, the necessary condition is solidness of the outermost layer of the particle, requiring the water activity to be below the quasi-equilibrium glass transition point. In the case of immersion mode nucleation, a $1 \mathrm{~nm}$ thick region in the near-surface bulk is required to be entirely liquefied before nucleation can occur in the immersion mode. For this purpose, a $2 \mathrm{~nm}$ thick region below the particle surface is finely resolved by multiple bulk layers (cf. Fig. S1).

\subsubsection{Bulk diffusion and bulk layer mixing}

Bulk diffusion of water is treated as kinetic flux, $J_{\mathrm{b} k, \mathrm{~b} k \pm 1}$, from one bulk layer ( $b k)$ to the next $(\mathrm{b} k \pm 1)$. Because layer thickness is not allowed to fall below the molecular resolution, concentrations in adjacent layers can differ significantly. As in Zobrist et al. (2011), this heterogeneity is accounted for with a virtual mixing scheme for the determination of bulk diffusivities between layers. In this scheme, the composition of a mixture of two subsequent bulk layers is determined and the bulk diffusion coefficient calculated according to the effective composition along the diffusion path. Scenarios with very low diffusivities and hence steep concentration gradients thus lead to situations in which a liquefied layer (high bulk diffusivity of water, $D_{\mathrm{H}_{2} \mathrm{O}}$ ) "softens" the subsequent glassy layer (low $D_{\mathrm{H}_{2} \mathrm{O}}$ ), facilitating further diffusion. Such a process can be seen as analogous to a dissolution process, in which the glassy matrix dissolves into nearby water-rich regions.

Diffusion of the organic matrix has been neglected for this study, because the organic molecules investigated here can be expected to diffuse much more slowly than water molecules. Also, in the glassy state, the organic molecules diffuse on a much longer timescale compared to the experimental timescale of minutes to hours (cf. Shiraiwa et al., 2011; Koop et al., 2011).

\subsubsection{Surface monolayers and surface softening}

The original KM-GAP uses a double monolayer approach to describe the particle surface, comprising a sorption layer and a quasi-static surface layer. In this study the quasi-static surface layer was replaced by a near-surface volume layer similar to that used in Shiraiwa et al. (2013a), which is more suitable for low diffusivity systems.

Surface-adsorbed water can lead to softening of the solid surface (Koop et al., 2011), thereby facilitating exchange between surface and first near-surface bulk layer. In the model, this is accounted for by introducing a surface softening scheme that estimates the surface-to-bulk transport rate by mixing a hypothetical water monolayer with a hypothetical bulk monolayer containing water and bulk material. Using the momentary molar fractions of water $\left(x_{\mathrm{b} 1, \mathrm{H}_{2} \mathrm{O}}\right)$ and organics $\left(x_{\mathrm{b} 1, \text { org }}\right)$ of the near-surface bulk layer, the effective surface coverages of water $\left(\theta_{\mathrm{ss}, \mathrm{H}_{2} \mathrm{O}}\right)$ and organics $\left(\theta_{\mathrm{ss}, \mathrm{org}}\right)$ at the surface bulk layer can be described as

$\theta_{\mathrm{ss}, i}=\frac{x_{\mathrm{b} 1, i} \cdot \sigma_{i}}{x_{\mathrm{b} 1, \mathrm{org}} \cdot \sigma_{\mathrm{org}}+x_{\mathrm{b} 1, \mathrm{H}_{2} \mathrm{O}} \cdot \sigma_{\mathrm{H}_{2} \mathrm{O}}}$, 
where $\sigma_{i}$ is the molecular cross section of species $i$ (i.e. water $\left(\mathrm{H}_{2} \mathrm{O}\right)$ or organics (org)). The weight fraction of organics in the "softened" surface is then given by

$$
w_{\mathrm{ss}, \text { org }, \text { mix }}=\frac{\frac{\theta_{\mathrm{ss}, \mathrm{org}}}{\sigma_{\mathrm{org}}} \cdot M_{\mathrm{org}}}{\frac{\theta_{\mathrm{ss}, \mathrm{org}}}{\sigma_{\mathrm{org}}} \cdot M_{\mathrm{org}}+\left(\frac{\theta_{\mathrm{ss}, \mathrm{H}_{2} \mathrm{O}}+1}{\sigma_{\mathrm{H}_{2} \mathrm{O}}}\right) \cdot M_{\mathrm{H}_{2} \mathrm{O}}},
$$

where $M_{\mathrm{org}}$ and $M_{\mathrm{H}_{2} \mathrm{O}}$ are the molar mass of organics and water. This process facilitates the initial water uptake into a glassy particle and leads (in most cases) to a sub-surface layer that is in equilibrium with the surrounding gas phase. In the temperature range relevant for immersion freezing, liquefaction of the surface was always obtained at the quasiequilibrium glass transition point due to the surface softening mechanism. At lower temperatures however (deposition regime), the particle surface was not always in quasiequilibrium with ambient humidity.

\subsection{Estimation of water diffusivity in SOA}

For model systems other than sucrose/water, no direct parameterization of water diffusivity in the full atmospherically relevant temperature and composition range is available to date. For compounds chemically similar to sucrose (i.e. organic polyols and acids), we present a scheme that enables estimation of bulk diffusivity data from glass transition and hygroscopicity data. Bulk diffusivity of water is parameterized using a Vogel-Fulcher-Tammann (VFT) approach (Vogel, 1921; Fulcher, 1925; Tammann and Hesse, 1926). The estimation scheme utilizes the structure of the VFT equation, Eq. (S9), and the physical interpretation of its parameters. The method can be described by the following set of assumptions.

1. Two similar organic substances act similarly in the way they approach the glass transition and thus have a similar fragility: $B_{\text {org1 }} \approx B_{\text {org2 }}$.

2. The same two substances have a similar diffusion coefficient in the high temperature limit: $A_{\text {org1 }} \approx A_{\text {org2 }}$.

3. A difference in glass transition temperatures $\left(T_{g, \text { org }}\right)$ between the two substances indicates a difference in Vogel temperatures $\left(T_{0, \text { org }}\right)$ of the same direction and (relative) magnitude:

$$
\frac{T_{0, \text { org } 1}}{T_{0, \text { org } 2}} \approx \frac{T_{\mathrm{g}, \text { org } 1}}{T_{\mathrm{g}, \text { org } 2}} .
$$

Thus, diffusivities within an organic substance can be estimated by knowledge of its glass transition curve relative to a known standard with similar chemical functionality. This approach requires knowledge of three parameters for inferring water diffusivity over the full temperature and composition

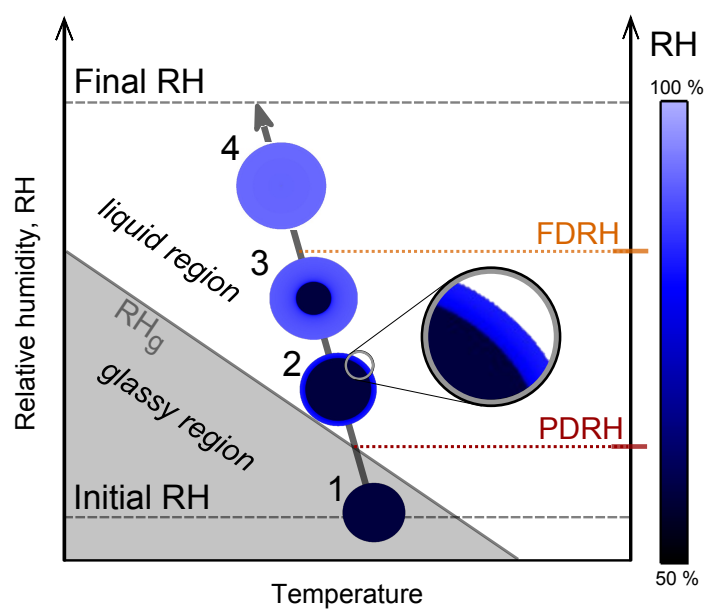

Figure 1. Schematic temporal evolution of particle morphology along a trajectory of an atmospheric updraft (grey arrow). Humidification of ambient air upon adiabatic expansion leads to liquefaction of initially glassy particles (dark blue colour, 1) via coreshell morphologies $(2,3)$ to liquid particles (light blue colour, 4). Whereas partial deliquescence (PDRH) coincides with $\mathrm{RH}_{\mathrm{g}}$, full deliquescence (FDRH) is delayed to much higher RH, indicating that diffusion processes occur on much longer timescales than humidification. The speed at which particles are humidified along the displayed trajectory corresponds to that typical of cloud chamber or environmental cell experiments $\left(0.1-1.5 \mathrm{~K} \mathrm{~min}^{-1}, 1-15 \% \mathrm{RH}\right.$ $\min ^{-1}$ ).

range: the hygroscopicity coefficient, $\kappa_{\text {org }}$, the glass transition temperature of the pure organic, $T_{\mathrm{g}, \text { org }}$, and the GordonTaylor coefficient $\left(k_{\mathrm{GT}}\right)$ of the aqueous organic mixture. For justification, more information on this procedure and a description of how the required input parameters were obtained, see Appendix A. For validation of the estimation scheme, we provide applications to literature ice nucleation experiments in Appendix B.

\section{Results and discussion}

\subsection{Particle morphology}

We investigate ice nucleation in glassy organic aerosols induced by changing ambient conditions during the updraft of an air parcel. In updraft events, adiabatic cooling leads to a decrease in temperature and a corresponding increase of relative humidity (RH). Humidification of air leads to water uptake into the particle phase, causing a humidity-induced phase transition that for glassy aerosol particles has been termed amorphous deliquescence (Mikhailov et al., 2009). This process is often kinetically limited by diffusion of water in the particle phase (Zobrist et al., 2011), so that a particle can be out of equilibrium when the timescale of humidification is shorter than that of diffusion. 
Amorphous deliquescence is a self-accelerating process since water acts as a plasticizer in the organic matrix (Mikhailov et al., 2009; Zobrist et al., 2011): water molecules taken up by the particle reduce the particle's viscosity and, hence, increase bulk diffusivity locally, thus accelerating the uptake of further molecules. The microphysical consequences of this mechanism are illustrated in Fig. 1, which shows the temporal evolution of particle morphology of a glassy organic aerosol particle exposed to a gradual increase in relative humidity (simulated atmospheric updraft, see also Movie S1). The quasi-equilibrium glass transition of the aqueous organic, $\mathrm{RH}_{\mathrm{g}}$, is shown in grey. With "quasiequilibrium glass transition", we denote the conditions under which a binary organic-water system would undergo amorphous deliquescence when humidification occurs sufficiently slowly so that equilibrium between ambient $\mathrm{RH}$ and water activity is always maintained. Humidification may be fast enough to cause a difference in phase state from equilibrium: water activity, colour-coded from dark blue (low water activity) to light blue (high water activity), trails behind ambient $\mathrm{RH}$ due to kinetic limitations in water diffusivity (Koop et al., 2011). Note that when using a constant $D_{\mathrm{H}_{2} \mathrm{O}}$, diffusion gradients appear less pronounced (cf. Fig. S2 and Movie S2). Hence, self-accelerating water diffusion leads to a sharpening of the diffusion gradient that can be close to the molecular length scale (Zobrist et al., 2011).

Several morphological stages can be distinguished during the humidification process in Fig. 1. Starting from a homogeneous, glassy particle (1), an increase in RH first leads to liquefaction of a thin outer layer and emergence of a core-shell morphology (2). This liquid outer layer grows in equilibrium with ambient relative humidity and also extends towards the particle centre by diffusion of water into the glassy organic matrix (3), leading to shrinkage of the residual glassy core until the particle is fully deliquesced (4). Thus, during the continuous amorphous deliquescence process two characteristic instants can be distinguished, each occurring at a different humidity: we define the partial deliquescence relative $h u$ midity (PDRH) as the point where a thin aqueous outer shell of the particle is homogeneously mixed and the shell's water activity is larger than that of the quasi-equilibrium glass transition. In this study we set the thickness of this surface shell to $1 \mathrm{~nm}$, corresponding to about five monolayers of water. We define the full deliquescence relative humidity (FDRH) as the point where the entire particle's water activity corresponds to that of a liquid (i.e. it is larger than that of the quasiequilibrium glass transition) and the water activity gradient from the surface to the particle core is less than $5 \%$. Note that, in the case of a sufficiently slow updraft, both PDRH and FDRH would occur at $\mathrm{RH}_{\mathrm{g}}$. In fact, the KM-GAP simulations suggest that, with updraft velocities typical of atmospheric conditions (e.g. $0.01-10 \mathrm{~m} \mathrm{~s}^{-1}$ ), PDRH often coincides with $\mathrm{RH}_{\mathrm{g}}$. In contrast, FDRH often extends far into the liquid region of the phase diagram, indicating the importance of kinetic limitations and implying that particles can contain glassy cores even at relative humidities above $\mathrm{RH}_{\mathrm{g}}$ due to slow water diffusion.

\subsection{Ice nucleation regimes}

Next, we investigate by kinetic model simulations the competition between amorphous deliquescence and ice nucleation during an atmospheric updraft. For our initial calculations we use sucrose as a proxy for organic aerosols since detailed physico-chemical parameterizations for water diffusivity, the RH-dependent equilibrium composition as well as glass transition data are available (Zobrist et al., 2011). The heterogeneous ice nucleation onset $\left(\mathrm{RH}_{\text {het }}\right)$ for sucrose was obtained from ice nucleation experiments by Baustian et al. (2013) and is shown as brown dashed lines in Fig. 2. Here we use the ice saturation ratio $S_{\text {ice }}$ as an indicator of humidity because it scales with $\mathrm{RH}$ according to $S_{\text {ice }}=$ $p_{\text {liq, }, 0}(T) / p_{\text {ice }}(T) \cdot \mathrm{RH}$, but is also a more direct indicator of the supersaturation of ice. $p_{\text {liq, } 0}$ and $p_{\text {ice }}$ indicate here the vapour pressures over pure supercooled water and over ice, respectively.

Figure 2 a shows results obtained with KM-GAP simulating the updraft of $100 \mathrm{~nm}$ sucrose particles for a wide range of temperatures. Each simulated trajectory started at ice saturation $\left(S_{\text {ice }}=1\right)$, as is often the case for cloud chamber or environmental cell experiments (Murray et al., 2010; Wang et al., 2012). Temperature was decreased so that the resulting humidification rate was constant at $1 \% \mathrm{RH} \mathrm{min}^{-1}$, corresponding to an atmospheric updraft of about $0.2 \mathrm{~m} \mathrm{~s}^{-1}$, typical of atmospheric gravity waves (Jensen et al., 2005). As expected the FDRH of sucrose particles, indicated by the red solid line, occurs significantly above $\mathrm{RH}_{\mathrm{g}}$ at all temperatures. The intersection of $\mathrm{RH}_{\text {het }}$ with $\mathrm{RH}_{\mathrm{g}}$ defines the upper temperature limit for deposition nucleation. Below this temperature, a sucrose particle is a glassy solid when $\mathrm{RH}_{\text {het }}$ is reached, and hence deposition ice nucleation may occur. Above this temperature, the particle is partially deliquesced when approaching $\mathrm{RH}_{\text {het }}$ and the glassy core of the particle may act as an IN for immersion freezing. The upper limit of the immersion freezing regime is given by the intersection of $\mathrm{RH}_{\text {het }}$ with the FDRH line. Above this temperature, particles are already fully deliquesced once $\mathrm{RH}_{\text {het }}$ is reached. Hence, these particles do not nucleate ice heterogeneously and freeze only at the homogeneous ice nucleation limit (green dashed line; Koop et al., 2000). Finally at $\sim 232 \mathrm{~K}$, the homogeneous ice nucleation limit coincides with water saturation (solid black line), and above this temperature the aerosol particles activate into cloud droplets consisting of supercooled water, thus representing the upper limit of the homogeneous ice nucleation regime.

The delay between the nominal quasi-equilibrium glass transition $\mathrm{RH}_{\mathrm{g}}$ and the actual full deliquescence at FDRH is governed by the competition between the humidification rate (synonymous to updraft velocity) and timescale for water diffusion within the particle bulk. FDRH will shift towards 

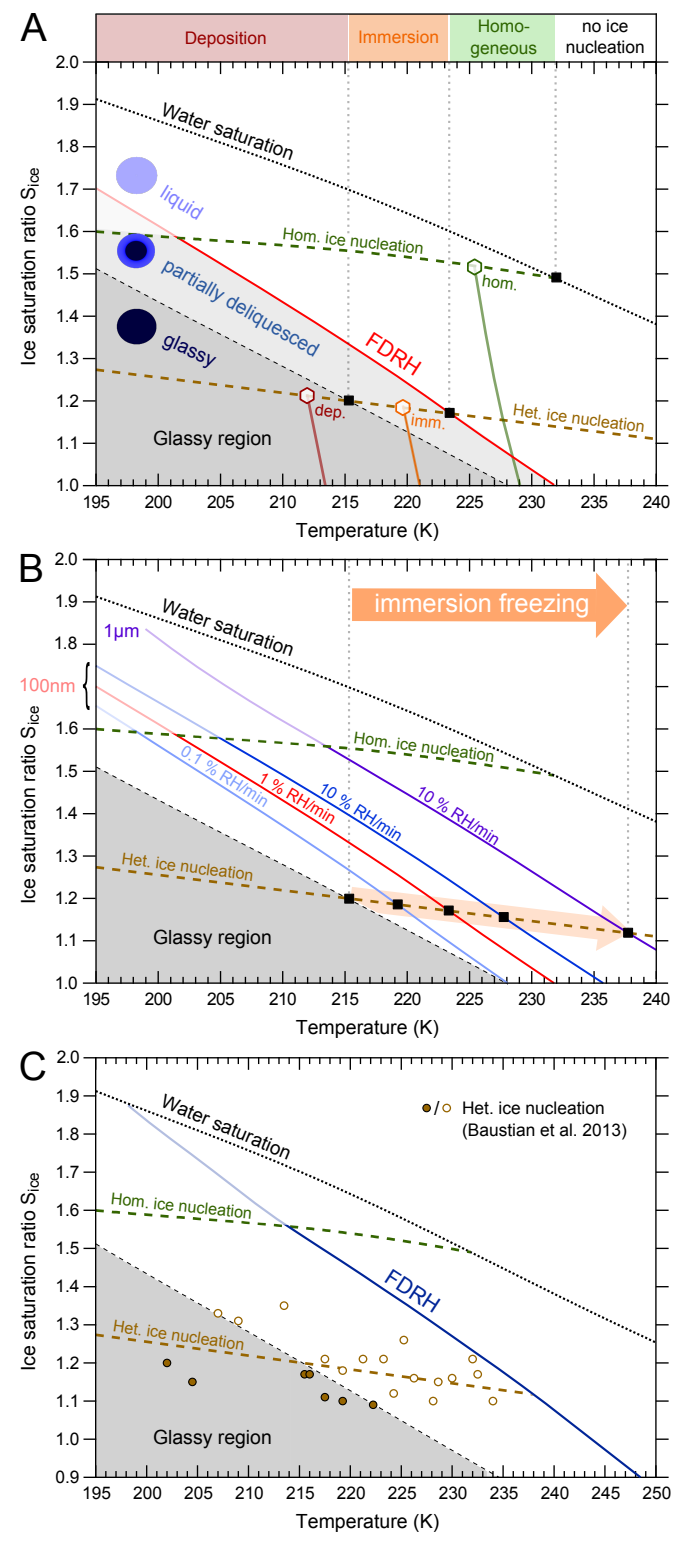

Figure 2. (a) Simulated regimes of heterogeneous and homogeneous ice nucleation in the humidification of sucrose particles. The red solid line indicates full deliquescence relative humidities (FDRH) for $100 \mathrm{~nm}$ particles exposed to a humidification rate of $1 \% \mathrm{RH} \mathrm{min} \operatorname{mos}^{-1}\left(\approx 0.2 \mathrm{~m} \mathrm{~s}^{-1}\right.$ atmospheric updraft). Example trajectories start at ice saturation, follow a constant dew point line and end at expected ice nucleation (hexagonal markers) with deposition (red), immersion (orange), and homogeneous (green) freezing. (b) Effects of different particles sizes and humidification rates on FDRH. The upper boundary for immersion freezing is extended to high temperatures for large particle radii and high humidification rates and is expected to occur up to $238 \mathrm{~K}$ for the most extreme scenario $\left(1 \mu \mathrm{m}, 10 \% \mathrm{RH} \mathrm{min}^{-1}\right.$, purple solid line). (c) Application to the experimental conditions in Baustian et al. (2013), i.e. $4 \mu \mathrm{m}$ particles humidified at a rate of $1 \% \mathrm{RH} \mathrm{min}^{-1}$, leads to FDRH that is able to explain all observed experimental ice onsets (brown circles). The thermodynamic glass transition divides the experimental data in events of deposition ice nucleation (closed circles) and immersion freezing (open circles). higher relative humidities when higher humidification rates are employed, as shown in Fig. 2b. For example, increasing the rate of humidification to $10 \% \mathrm{RH} \mathrm{min}^{-1}$, a value corresponding to an updraft velocity of about $2 \mathrm{~m} \mathrm{~s}^{-1}$ and commonly reached in convective updrafts (Jensen et al., 2005), shifts the FDRH line upwards (solid dark blue line) and thus its intersection with the $\mathrm{RH}_{\text {het }}$ line towards higher temperatures. Accordingly, decreasing the updraft velocity to $0.02 \mathrm{~m} \mathrm{~s}^{-1}$, a value found in large-scale, synoptic updrafts (Jensen et al., 2005), leads to an FDRH (solid light blue line) much closer to the quasi-equilibrium glass transition $\mathrm{RH}_{\mathrm{g}}$. Moreover, an increase in particle size delays the deliquescence process (indicated by the solid purple line), since it increases the timescale of diffusion. The range of the immersion freezing regime thus strongly depends on ambient conditions and is extended towards higher temperatures in fast updrafts and for large particles.

Laboratory ice nucleation measurements with sucrose particles (Baustian et al., 2013) are used to validate our model calculations of ice nucleation regimes in Fig. 2c. Baustian et al. (2013) used optical microscopy in conjunction with a cold stage to detect ice nucleation on glassy sucrose particles $\left(4 \mu \mathrm{m}\right.$ diameter) during humidification $\left(1 \% \mathrm{RH} \mathrm{min}{ }^{-1}\right)$, leading to the nucleation onsets shown in Fig. 2c (brown markers). A range of simulations mimicking the experimental conditions at different starting temperatures leads to a continuous FDRH curve (solid blue line) over the entire temperature range. For details on the calculations see Appendix B. The modelled FDRH curve correctly confines the region below which heterogeneous ice nucleation is observed in the experiments. Based on our calculations, the experimental data points below $\mathrm{RH}_{\mathrm{g}}$ (full brown circles) can be assigned to the deposition nucleation regime, whereas points between $\mathrm{RH}_{\mathrm{g}}$ and FDRH (open brown circles) can be assigned to immersion freezing. Additional analyses for validation have been performed for other types of organic particles (Appendix B, Figs. B1 and B2).

\subsection{Biogenic and anthropogenic SOA}

In order to apply our kinetic model to ice nucleation in SOA, estimates of $D_{\mathrm{H}_{2} \mathrm{O}}$ in SOA material have been inferred. Four major SOA precursors were chosen to represent biogenic and anthropogenic origin, respectively: $\alpha$-pinene and isoprene, as well as naphthalene and dodecane. Each of these SOA is represented by a choice of marker compounds taken from the literature (cf. Table S1). Water diffusivities are estimated using the scheme described in Sect. 2.2. The heterogeneous ice nucleation onset $\left(\mathrm{RH}_{\text {het }}\right.$, brown dashed line) for SOA was obtained from laboratory measurements by Wang et al. (2012) and Schill et al. (2014) as derived in Fig. A1. Hygroscopicities of the various SOA were taken from Lambe et al. (2011), who suggested that $\kappa_{\text {org }}$ can be parameterized independently of SOA type as function of $\mathrm{O} / \mathrm{C}$ ratio. In all simulations, 


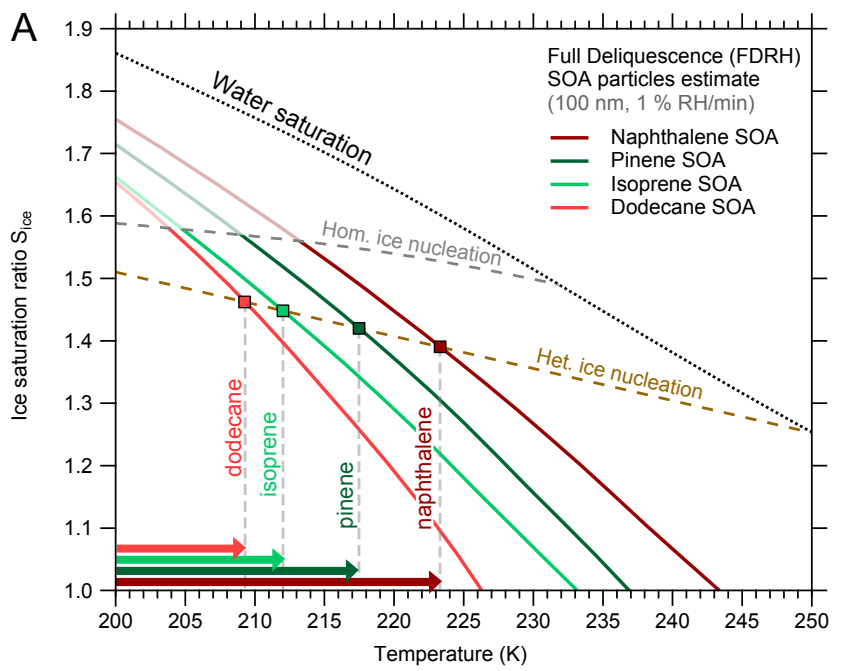

B

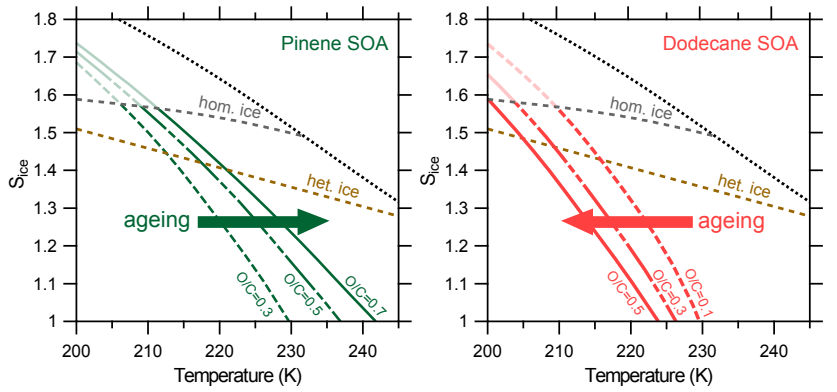

Figure 3. (a) Simulated humidification of SOA particles from the four different precursors $\alpha$-pinene, isoprene, dodecane and naphthalene. Naphthalene SOA (dark red) shows the latest deliquescence, whereas dodecane SOA (light red) liquefied rather early in the simulations. The two biogenic SOA estimates lie between both extremes with pinene SOA (dark green) showing slightly later deliquescence than isoprene SOA. Intercepts (square markers) with a heterogeneous nucleation onset typical of SOA (brown dashed line) indicate upper temperature limits for immersion freezing (arrows on $x$ axis). The effect of particle ageing also depends on precursor type: pinene SOA (b) shows hardening upon increase in $\mathrm{O} / \mathrm{C}$ (indicated by higher FDRH), whereas dodecane SOA (c) exhibits softening (indicated by lower FDRH). Similarly, isoprene and naphthalene SOA show only moderate hardening and softening, respectively (Fig. S5).

particles of $100 \mathrm{~nm}$ diameter were humidified at a rate of $1 \%$ RH $\min ^{-1}$.

Figure 3a shows the simulation results of FDRH for all four precursor types. Naphthalene SOA is observed to fully deliquesce last due to the high estimated glass transition temperature and low hygroscopicity (cf. Table A1), followed by $\alpha$-pinene and isoprene. Dodecane SOA showed the earliest deliquescence, reflecting the low glass transition temperature of pure dodecane SOA of $\sim 210 \mathrm{~K}$. By comparison of FDRH with measured $\mathrm{RH}_{\text {het }}$ on SOA, compound-specific upper temperature limits for heterogeneous ice nucleation on SOA particles can be determined (arrows on $x$ axis, values are given in Table S2). Uncertainty estimates for FDRH and $\mathrm{RH}_{\mathrm{g}}$ of all four precursors classes are given in Fig. S4.

For the calculations in Fig. 3a, we chose an average oxidation state typically observed for SOA from the respective precursor. The atomic oxygen to carbon ratio $(\mathrm{O} / \mathrm{C})$ increases upon chemical ageing, thereby affecting hygroscopicity (Lambe et al., 2011) and glass transition temperature (Fig. A2). The resulting effects of chemical ageing on modelled FDRH are shown for $\alpha$-pinene and dodecane SOA as examples in Fig. $3 \mathrm{~b}$ and c, respectively. For $\alpha$-pinene SOA (Fig. 3b), a higher $\mathrm{O} / \mathrm{C}$ results in hardening of the organic material with ageing, leading to an FDRH increase, whereas for dodecane SOA (Fig. 3c) a higher $\mathrm{O} / \mathrm{C}$ results in softening, thus leading to earlier deliquescence and an FDRH decrease.

The observed effects can be explained by the competition between a simultaneous increase of hygroscopicity with $\mathrm{O} / \mathrm{C}$ and an increasing glass transition temperature of the pure organic matrix due to stronger molecular interactions in the highly oxidized organic material. A higher glass transition value enhances the rigidness of the pure organic matrix, whereas a higher hygroscopicity enhances the amount of water taken up by the aqueous organic mixture at a given humidity and thus its plasticizing effect.

Figure 4 illustrates this competition by displaying estimated characteristic timescales of water diffusion in $100 \mathrm{~nm}$ diameter SOA particles at $220 \mathrm{~K}$ as a function of hygroscopicity $\left(\kappa_{\mathrm{org}}\right)$ and glass transition temperature of the pure organic matrix $\left(T_{\mathrm{g}, \mathrm{org}}\right)$. Dotted contour lines show characteristic mass transport times associated with the diffusion coefficient $D_{\mathrm{H}_{2} \mathrm{O}}$ (Shiraiwa et al., 2011). Coloured oval shapes indicate estimated ranges of $\kappa_{\mathrm{org}}$ and $T_{\mathrm{g}, \text { org }}$ for the four SOA precursor classes, for three different oxidation states each (cf. Table A1). The arrows pointing from the lowest to the highest oxidation state reveal that both $\kappa_{\text {org }}$ and $T_{\mathrm{g}, \text { org }}$ increase with $\mathrm{O} / \mathrm{C}$. The slope of these arrows when compared to the slope of the contour lines indicates whether a compound undergoes hardening (steeper slope of arrow) or softening (shallower slope of arrow) during the ageing process. Apparently, both biogenic SOA types undergo hardening upon ageing, whereas the two anthropogenic SOA types undergo softening, with the strongest effects for pinene and dodecane SOA.

The area between $1 \mathrm{~s}$ and $1 \mathrm{~h}$ represents the timescale of atmospheric updraft processes. For SOA in this range, diffusion processes occur on the same timescales as typical air parcel updrafts, and the predominant cloud formation process depends strongly on atmospheric conditions. All four SOA types fall within or beneath this range, indicating the importance of the actual updraft velocity for ice nucleation on glassy aerosol particles. But it is also obvious that SOA particles from naphthalene are most likely to be subject to kinetic effects and may thus preferably act as IN. 
Water diffusion time scales in SOA $\left(220 \mathrm{~K}, \mathrm{~S}_{\mathrm{ice}}=1.45, \mathrm{~d}_{\mathrm{p}}=100 \mathrm{~nm}\right)$

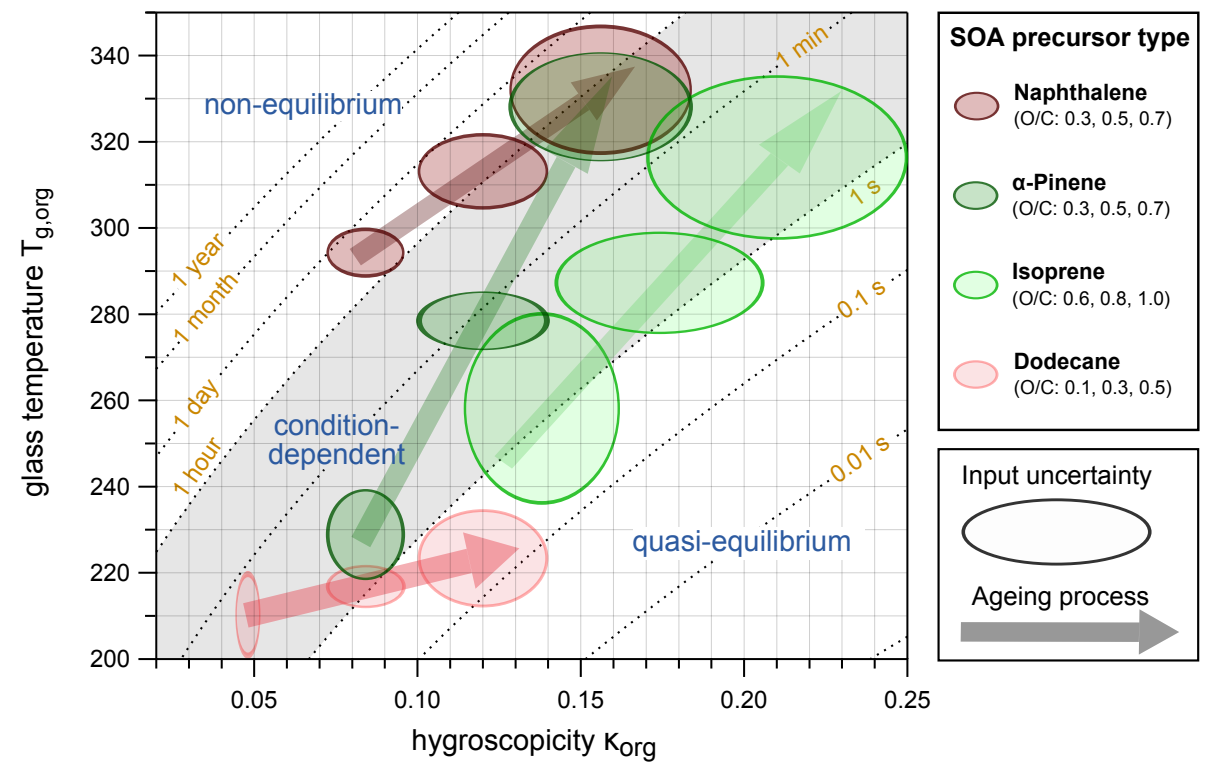

Figure 4. Characteristic timescales of water diffusion in SOA as a function of hygroscopicity, $\kappa_{\mathrm{org}}$, and glass transition temperatures of the

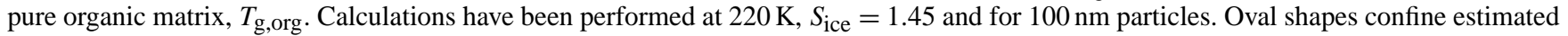
ranges in $\kappa_{\text {org }}$ and $T_{\mathrm{g}, \text { org }}$ for the four SOA types in three different oxidation states (Appendix A and Table A1). The grey area indicates the timescale of typical atmospheric updrafts $(1 \mathrm{~s}$ to $1 \mathrm{~h}$ ) and thus divides the plot into areas of quasi-equilibrium and non-equilibrium water diffusion. Within the grey area, the relative speed of both processes depends upon the actual atmospheric conditions. The ageing process is indicated by arrows pointing from regions of low $\mathrm{O} / \mathrm{C}$ to regions of high $\mathrm{O} / \mathrm{C}$.

\subsection{Model uncertainties}

The model results presented in this study are subject to various types of uncertainty. Among these are uncertainties arising from model assumptions such as the validity of first-order Fickian diffusion and the applied schemes for bulk mixing and surface softening (Sects. 2.1.2 and 2.1.3). At present there is a lack of fundamental chemical and physical knowledge for describing these processes in aqueous binary or multicomponent systems. We note, however, that the approach taken here is in agreement with the sparse data on water diffusivities in aqueous organic systems (Zobrist et al., 2011; Shiraiwa et al., 2013b; Lienhard et al., 2014; Price et al., 2014). Model results obtained for aqueous sucrose (Fig. 2) are expected to be reliable because the thermodynamic and kinetic parameters of this benchmark system are well studied and agree within the literature (e.g. Zobrist et al., 2011; Price et al., 2014); on the other hand, model results obtained for SOA (Fig. 3) are subject to larger uncertainties as detailed in the following.

The model neglects liquid-liquid phase separation in the aqueous organic phase (You et al., 2014) by assuming that all SOA components are miscible with water over the entire concentration and temperature range. We note that, for SOA types that typically show only low $\mathrm{O} / \mathrm{C}$ ratios (e.g. SOA from long-chain aliphatic precursors such as dodecane), in- soluble fractions may become important for ice nucleation (see discussion in Sect. B2).

Volatilization of organic material has not been included in the calculations presented above since vapour pressures of typical SOA marker compounds are low under the low temperature conditions employed in this study (Huisman et al., 2013; O'Meara et al., 2014).

Self-diffusion of SOA material has been neglected as diffusion timescales of large organic molecules exceed those of small guest molecules in the SOA matrix by orders of magnitudes (Koop et al., 2011; Shiraiwa et al., 2011).

Minor model uncertainty comes from parameters determining the volume concentration of organic molecules at a given organic mass fraction, i.e. average molar mass $M_{\text {org }}$ of the organics and density of the aqueous organic mixture (cf. Table S3). Variation by $100 \mathrm{~g} \mathrm{~mol}^{-1}$ in $M_{\text {org }}$ showed no effect on model results; varying $\rho_{\text {org }}$ by $0.1 \mathrm{~g} \mathrm{~cm}^{-3}$ showed only a slight influence on aerosol deliquescence humidity on the order of $1 \% \mathrm{RH}$.

The arguably largest source of uncertainty is insufficient knowledge of the thermodynamic input parameters required for the diffusivity estimation scheme $\left(\kappa_{\mathrm{org}}, T_{\mathrm{g}, \mathrm{org}}, k_{\mathrm{GT}}\right.$, cf. Appendix A). In addition to the general assumptions made in that scheme and the uncertainties in the sucrose parameterization used within the diffusivity estimation scheme, uncertainties in input parameters propagate into an uncertainty in $D_{\mathrm{H}_{2} \mathrm{O}}$, which we assess in Figs. S4 and S6. Figure S4 
shows the uncertainty for each specific SOA precursor and a particular $\mathrm{O} / \mathrm{C}$ ratio by propagating the maximum deviation estimates in $\kappa_{\text {org }}$ and $T_{\mathrm{g} \text {,org }}$ given in Table A1. Figure S6 shows the full uncertainty towards single model input parameters irrespective of precursor or oxidation state. Among these, $\kappa_{\text {org }}$ seems to be the largest source of uncertainty as the model results are sensitive towards $\kappa_{\text {org }}$ and its numerical value is subject to a rather large variability for atmospherically relevant organic substances (Koop et al., 2011; Lambe et al., 2011; Rickards et al., 2013). Due to a lack of consistent experimental data, a constant $\kappa_{\text {org }}$ is used in this study to parameterize hygroscopicity over the entire concentration and temperature range.

Laboratory experiments that directly probe diffusivity within SOA at room temperature and also at low temperature are highly desirable, as have been done for sucrose and a few other single-compound proxies (Tong et al., 2011; Zobrist et al., 2011; Bones et al., 2012; Lienhard et al., 2014; Price et al., 2014). Moreover, experiment-based water activity parameterizations over a large temperature range are needed, because at least some water-soluble organic oligomers/polymers show a strong temperature dependence of water activity for aqueous mixtures of constant composition (Zobrist et al., 2003). Such improvements would reduce the model uncertainty in future modelling studies substantially.

Another type of uncertainty arises from uncertainty in heterogeneous ice nucleation onsets. To date, little is known about the exact microphysical mechanism by which amorphous organics nucleate ice heterogeneously (Wagner et al., 2012; Marcolli, 2014; Schill et al., 2014). Reported ice nucleation onsets of glassy particles span wide ranges and are most likely substance or substance class-specific (Wilson et al., 2012; Schill et al., 2014). Thus, further laboratory experiments are needed that reveal details on the ice nucleation mechanism and that allow predictions of ice nucleation ability for a wide variety of substances.

\section{Atmospheric implications of glassy organic IN}

Organic aerosols can induce cloud formation via many different pathways depending on ambient conditions and composition. At high temperature and high humidity, liquid organic particles can act as cloud condensation nuclei (CCN). At lower temperatures, they facilitate formation of ice crystals. Figure 5 summarizes how the phase state and morphology of atmospheric organic aerosol particles may vary upon changes in ambient relative humidity (humidity-induced phase transitions). Upon humidifying, the phase state changes from amorphous solid (glassy) over a partially deliquesced state with a solid core residual coated by a liquid shell to a fully deliquesced liquid. Upon drying, the transition may occur via an inverse core-shell morphology, i.e. a liquid coated by a solid shell. Consequently, the particle phase state determines

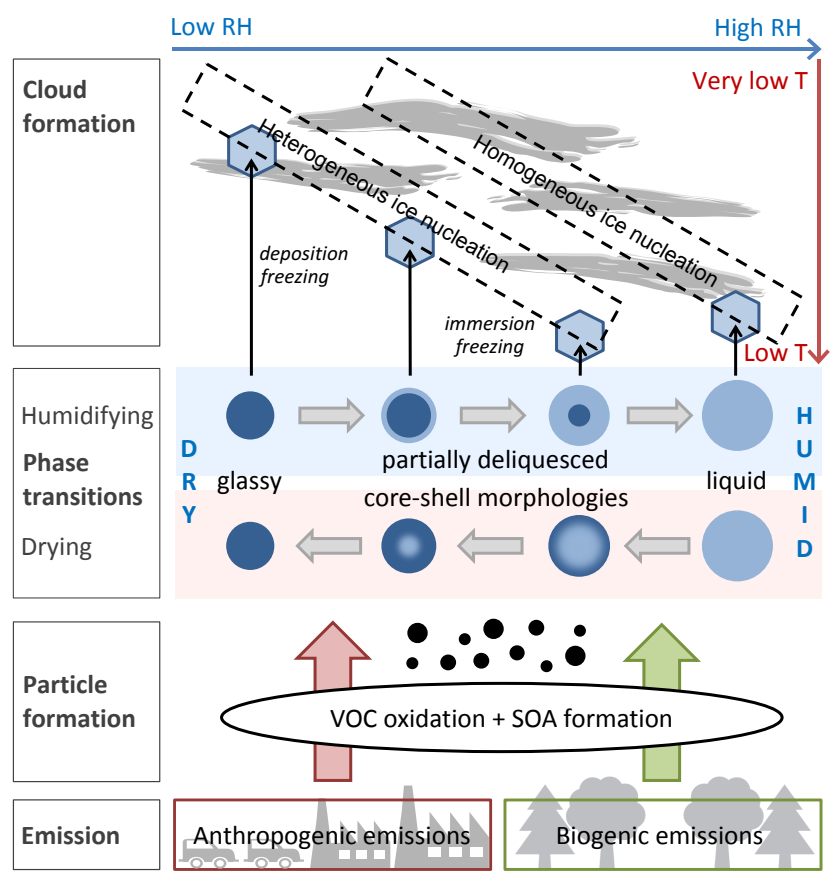

Figure 5. Overview of processes in organic aerosol particles affecting atmospheric cloud formation. Particles form by oxidation of volatile organic compounds (VOCs) originating from anthropogenic and biogenic emissions. The dominating cloud formation process depends on particle phase state, which is a function of temperature and humidity. Humidity-induced phase transitions between phase states may be kinetically limited and occur under formation of partially deliquesced particles with core-shell morphologies. Glassy or partially deliquesced particles are able to undergo heterogeneous ice nucleation, occurring at lower relative humidity or higher temperature than homogeneous ice nucleation of liquid particles.

the active ice nucleation pathway: glassy solids can nucleate ice in the deposition mode, partially deliquesced particles with core-shell morphologies may act as IN in the immersion mode and liquid particles nucleate ice homogeneously, at significantly higher ice supersaturation.

From the SOA types investigated in this study, aromatic SOA or highly aged $\alpha$-pinene SOA may persist in a glassy state to the highest temperatures and humidities and may thus facilitate heterogeneous ice nucleation at temperatures of up to $225 \mathrm{~K}$. Below $210 \mathrm{~K}$, SOA particles from all precursors are expected to be in the glassy state required for heterogeneous ice nucleation. Our microphysical simulations suggest a potential anthropogenic influence of IN from emission of aromatic VOCs and by providing high oxidative capacities in urban areas leading to an increase of ice nucleation in and on glassy organic particles.

Compared to typical atmospheric IN such as dust, soot and biological particles, glassy organic particles require temperatures below $\sim 230 \mathrm{~K}$ to nucleate ice heterogeneously (Hoose and Möhler, 2012). This restriction confines their atmospheric activity range to the upper troposphere-lower 
stratosphere region. Our simulations confirm that the glassy state is prevalent only up to temperatures of about $200-240 \mathrm{~K}$ under typical atmospheric humidities $\left(S_{\text {ice }} \approx 1\right)$, depending on composition.

In this study we show a strong interplay between diffusion timescales in the atmosphere and atmospheric updraft speeds: the stronger the updraft and the larger the particle size, the more kinetic limitations delay the liquefaction of glassy particles. These findings also imply that an ice nucleation onset determined in laboratory studies needs to be interpreted carefully in order to apply it to realistic atmospheric parameters, i.e. humidification rate, particle size and starting humidity. Kinetic limitations are already pronounced at the smallest atmospherically relevant updraft velocities of $0.02 \mathrm{~m} \mathrm{~s}^{-1}$. When humidification is fast (e.g. in convective updrafts), the glassy state may persist well above its quasi-equilibrium boundaries. Our simulations on sucrose and SOA particles suggest a shift of the humidity-induced glass transition to higher temperatures by about $5 \mathrm{~K}$ when updraft velocities are increased by a factor of 10 . Also, the history of an organic particle has effects on its water uptake properties: particles that were equilibrated at lower humidity are expected to deliquesce at higher ice supersaturation. In situations where particles are both equilibrated in dry air $\left(S_{\text {ice }}<0.9\right)$ and elevated quickly, upper temperature limits for immersion freezing on glassy organics might reach much higher values than the conservative estimates given in this study. Thus, also ice nucleation in mid-altitude clouds may be affected by this heterogeneous ice nucleation pathway.
This study outlines the basic physico-chemical relations and makes a first attempt in quantifying temperature limits for heterogeneous ice nucleation by four generic types of SOA, but further laboratory and modelling studies are needed to provide a comprehensive set of parameterizations to be used in atmospheric models. To assess the global importance of ice nucleation by SOA particles and to quantify the associated aerosol effects on climate, studies with largescale computational models are needed. As small-scale kinetic processes cannot be treated explicitly in these kinds of models, parameterizations are required that include dependencies on temperature, relative humidity, updraft velocity, particle size and composition. 


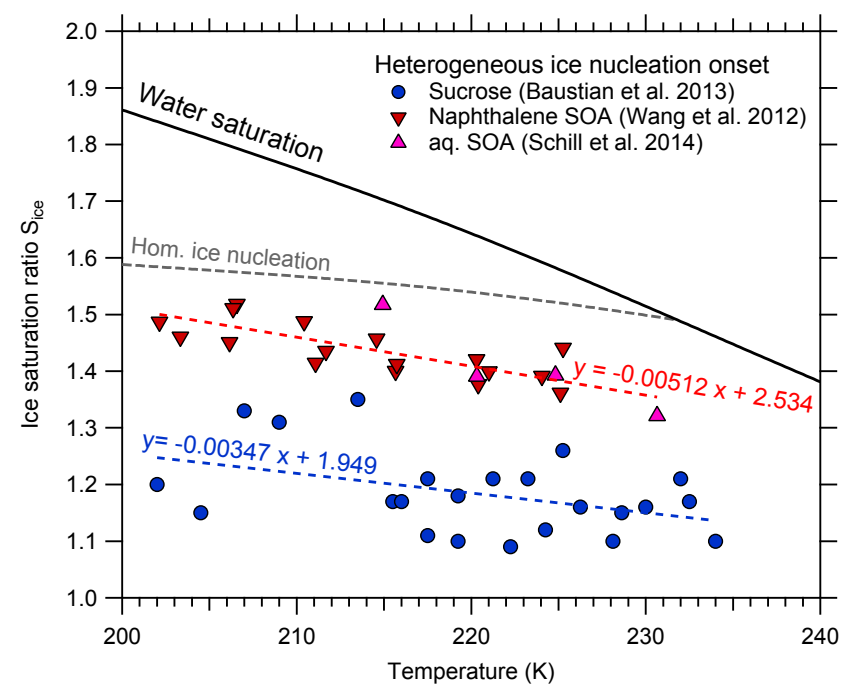

Figure A1. Determination of heterogeneous ice nucleation onsets. For sucrose, data from Baustian et al. (2013) (blue circles) are fitted. For SOA, deposition freezing data on naphthalene SOA from Wang et al. (2012) (red downward triangles) as well as nucleation data on aqSOA from Schill et al. (2014) (pink upward triangles) are used. The resulting linear regression fits (blue and red dashed lines) lie significantly below the homogeneous nucleation limit and are displayed along with their parameterizations.

\section{Appendix A: Details on the estimation of bulk diffusivities from glass transition and hygroscopicity data}

\section{A1 Justification of the method}

Even though the estimation scheme described in Sect. 2.2 represents a rather crude estimation of water diffusivities, it builds on basic physical principals: in solutions of chemically similar organic substances (like the mixture of highly functionalized organic species in SOA), the types of molecular interactions are mostly hydrogen bonds and dispersion interactions, irrespective of the actual composition. Differences in diffusive properties are to a substantial degree due to factors such as molar mass and shape, both of which directly affect the glass transition temperature (Koop et al., 2011). The way by which the glass transition is approached is not affected strongly by the SOA type, as all organic compounds relevant for SOA are fragile glass formers (Angell, 1985). The proposed method is consistent with the following previous studies.

Rampp et al. (2000) used nuclear magnetic resonance (NMR) spectroscopy to determine water diffusion coefficients in different carbohydrate matrices (sucrose, allosucrose, leucrose, trehalose) and fitted VFT parameters to the temperature and concentration-dependent data sets. Overall, similar VFT parameters $A$ and $B$ were found for these chemically similar substances, even though $D_{\mathrm{H}_{2} \mathrm{O}}$ seemed to de-

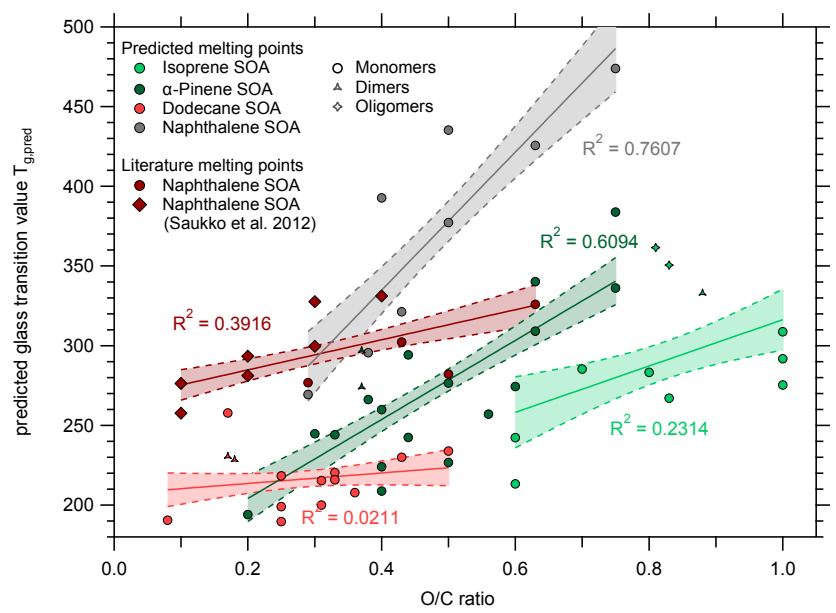

Figure A2. Predicted glass transition values of SOA marker substances as a function of $\mathrm{O} / \mathrm{C}$ ratio. The predicted $T_{\mathrm{g} \text {,org }}$ exhibits a linear correlation with $\mathrm{O} / \mathrm{C}$ for each of the four SOA systems. Solid lines are robust linear regressions using a bisquare weighting function and shaded areas are confidence intervals at the $1 \sigma$ level. Anthropogenic aliphatic SOA constituents show the lowest values of $T_{\mathrm{g}, \text { org }}$ and a weak dependence on $\mathrm{O} / \mathrm{C}$. In contrast, aromatic SOA shows the highest glass transition values despite a rather low average $\mathrm{O} / \mathrm{C}$ ratio.

Table A1. Assumed physical properties of SOA classes for use in conjunction with the diffusivity estimation scheme.

\begin{tabular}{lrccc}
\hline SOA Class & $\mathrm{O} / \mathrm{C}$ & $T_{\mathrm{g}, \mathrm{org}}(\mathrm{K})$ & $k_{\mathrm{GT}}$ & $\kappa_{\mathrm{org}}$ \\
\hline \multirow{3}{*}{$\alpha$-Pinene } & 0.3 & $228.9 \pm 10.6$ & 2.5 & $0.084 \pm 0.012$ \\
& 0.5 & $278.5 \pm 7.0$ & 2.5 & $0.120 \pm 0.020$ \\
& 0.7 & $328.1 \pm 12.8$ & 2.5 & $0.156 \pm 0.028$ \\
\hline \multirow{3}{*}{ Isoprene } & 0.6 & $258.2 \pm 22.2$ & 2.5 & $0.138 \pm 0.024$ \\
& 0.8 & $287.2 \pm 11.9$ & 2.5 & $0.174 \pm 0.032$ \\
& 1.0 & $316.3 \pm 19.1$ & 2.5 & $0.210 \pm 0.040$ \\
\hline \multirow{3}{*}{ Naphthalene } & 0.3 & $294.2 \pm 5.7$ & 2.5 & $0.084 \pm 0.012$ \\
& 0.5 & $313.1 \pm 8.8$ & 2.5 & $0.120 \pm 0.020$ \\
& 0.7 & $332.0 \pm 15.0$ & 2.5 & $0.156 \pm 0.028$ \\
\hline \multirow{3}{*}{ Dodecane } & 0.1 & $210.3 \pm 9.7$ & 2.5 & $0.048 \pm 0.004$ \\
& 0.3 & $216.8 \pm 5.1$ & 2.5 & $0.084 \pm 0.012$ \\
Koop SOA & - & $223.4 \pm 11.4$ & 2.5 & $0.120 \pm 0.020$ \\
\hline
\end{tabular}

pend strongly on organic mass fraction, thus supporting assumptions 1 and 2 in Sect. 2.2. The observed concentration dependence was described almost exclusively by a change in $T_{0}$, with only small trends in $A$ and minor variation in $B$, possibly due to experimental error, thus supporting assumption 3 in Sect. 2.2.

Angell (1997) investigated the correlation of Kauzmann temperatures $T_{\mathrm{k}}$ with Vogel temperatures $T_{0}$ and found their ratio to be close to unity. The ratio of $T_{\mathrm{g}}$ to $T_{0}$ has been shown to be confined to a narrow range between $1.07<T_{\mathrm{g}} / T_{0}<$ 1.82 for a wide variety of strongly different substances. This 
ratio seems to be correlated in magnitude to the substance's fragility (i.e. VFT parameter $B$ ), with high fragilities implying high $T_{\mathrm{g}} / T_{0}$ ratios. Conversely, the assumption of similar fragilities (assumption 2) directly points towards similar $T_{\mathrm{g}} / T_{0}$ ratios (assumption 3 ). Accordingly, deducing Vogel temperatures $T_{0}$ from glass transition properties seems reasonable.

\section{A2 Estimation of glass transition temperatures $T_{\mathrm{g}, \mathrm{org}}$}

The proposed estimation scheme enables the prediction of bulk diffusion coefficients only from knowledge of glass transition values for the desired $\mathrm{RH}$ range. The glass transition curve can be described by three parameters: the glass transition temperature of the pure molecular compound, $T_{\mathrm{g}, \text { org }}$; the Gordon-Taylor constant, $k_{\mathrm{GT}}$, of the aqueous organic mixture; and the hygroscopicity, $\kappa_{\text {org }}$, for translating composition into water activity. $T_{\mathrm{g} \text {,org }}$ exhibits a linear correlation with melting point, $T_{\mathrm{m}}$, also known as the BoyerBeaman rule (Koop et al., 2011). $T_{\mathrm{m}}$ can be estimated by group contribution models with knowledge of the chemical structure. We use the melting point prediction model of UPPER (Unified Physical Property Estimating Relationships) as presented by Jain and Yalkowsky (2006) and Jain et al. (2004).

Table S1 shows our choice of marker substances for four different types of SOA along with molar mass, melting points predicted with UPPER and predicted glass transition values based on the Boyer-Beaman rule. The SOA groups were chosen to include SOA from the most commonly studied precursors and are derived from one specified precursor substance each. The groups " $\alpha$-pinene" and "isoprene" represent SOA from biogenic origin, whereas "naphthalene" and "dodecane" are our choice for precursors of anthropogenic origin.

The group " $\alpha$-pinene" contains compounds characteristic of photooxidation and ozonolysis of the biogenic SOA precursor $\alpha$-pinene, which has been chosen as a proxy for the different monoterpene VOCs responsible for biogenic SOA formation. The list contains compounds with the highest yields according to the MCM-based simulations of Shilling et al. (2009) as well as those of Zuend and Seinfeld (2012), who also included two dimer substances. Furthermore, we included 3-MBTCA, a highly oxidized pinene derivative found in ambient samples (Szmigielski et al., 2007) as well as terpenylic acid, a tracer for fresh SOA, along with two of its derivatives (Claeys et al., 2009).

The group "isoprene" contains isoprene-derived compounds found in ambient and laboratory aerosol as suggested by Surratt et al. (2006) and references therein. These authors also proposed a high contribution of esterification products with 2-methylglyceric acid as monomeric unit to SOA mass. Table S1 lists these oligomers up to the tetramer level, where predicted glass transition values start to level off.
The group "naphthalene" represents typical products originating from the oxidation of anthropogenic aromatic precursors. Note that for highly functionalized aromatic compounds, UPPER predicts unusually high values for $T_{\mathrm{m}}$, which are inconsistent with observations. For example, phthalic acid melts under decomposition (presumably anhydrate formation) at $403 \mathrm{~K}$ (Lide, 2005), whereas UPPER suggests a melting point of about $539 \mathrm{~K}$. For this reason, we used only those naphthalene oxidation products for which literature melting points are known, such as the substances given in Saukko et al. (2012) and a number of compounds listed in Kautzman et al. (2010). Note that for the same reason we did not include oligomerization products to the "naphthalene" group. Oligomerization is however also expected for aromatic SOA, shown e.g. by Kalberer et al. (2004), which would lead to higher $T_{\mathrm{g}, \text { org }}$ (Koop et al., 2011). For these reasons, our estimates for aromatic SOA materials may be regarded as a conservative estimate.

The group "dodecane" in Table S1 lists oxidized organics derived from the $\mathrm{C} 12$ straight-chain alkanes to represent the family of similar compounds originating from aliphatic VOCs of anthropogenic origin. The list is a selection from the comprehensive chemical mechanism in Yee et al. (2012) and three compounds from those suggested by Zhang et al. (2014).

The resulting glass transition values are presented in Fig. A2 as a function of atomic $\mathrm{O} / \mathrm{C}$ ratio, and a clear positive correlation is observed within each group of compounds. Such a correlation between $T_{\mathrm{g} \text {,org }}$ and $\mathrm{O} / \mathrm{C}$ has been supported by recent $T_{\mathrm{g}}$ measurements of mixtures of $\alpha$-pinene-derived oxidation compounds (Dette et al., 2014). In Fig. A2, the solid lines are obtained by linear regressions of the glass transition values using a bisquare weighting function and shaded areas are confidence intervals at the $1 \sigma$ level. The chosen marker compounds occupy compoundspecific ranges of $\mathrm{O} / \mathrm{C}$ values, which is in part due to a different carbon number in the precursor molecule. To estimate a value characteristic for a mixture of the single compounds, we choose three values of $\mathrm{O} / \mathrm{C}$ ratios that are typical of the respective group and take at each of those values the corresponding $T_{\mathrm{g}, \text { org }}$ that arises from the linear fit. The errors are then given by the extension of confidence bands at each point. The results are shown in Table A1.

\section{A3 Estimation of Gordon-Taylor constants $\boldsymbol{k}_{\mathrm{GT}}$}

Gordon-Taylor constants are necessary to estimate the glass transition temperatures of compound mixtures. Zobrist et al. (2008) determined Gordon-Taylor constants for a variety of atmospherically relevant substances and SOA proxies. However, data are sparse when compared to the wide structural variety of compounds in SOA, and no clear correlation can be drawn from the molecular structure. For this reason, Koop et al. (2011) recommended the use of a mean GordonTaylor constant of $k_{\mathrm{GT}}=2.5 \pm 1$ (cf. Table A1). Figure S6 
shows the temperature dependence of FDRH in calculations similar to Figs. 2 and 3, this time using the best guess parameters recommended in Koop et al. (2011). The uncertainty in FDRH that arises from the given input parameter ranges is shown (grey shaded), and also the specific uncertainty from varying $k_{\mathrm{GT}}$ between 1.5 and 3.5 is highlighted (orange shaded).

\section{A4 Estimation of hygroscopicities $\kappa_{\text {org }}$}

The hygroscopicity of a compound can be expressed by a single parameter $\kappa_{\text {org }}$, which is strongly correlated to its degree of oxidation (Petters and Kreidenweis, 2007; Lambe et al., 2011). A typical value for $\kappa_{\text {org }}$ in biogenic SOA particles collected in pristine rainforest environments is 0.1 (Gunthe et al., 2009), which was also used by Koop et al. (2011) for their estimation of glass transition values in biogenic SOA.

For estimation of $\kappa_{\mathrm{org}}$, we use the parameterization of Lambe et al. (2011) that correlates the O/C ratio of secondary organic material to its hygroscopicity, Eq. (A1).

$\kappa_{\text {org }}=(0.18 \pm 0.04) \cdot \mathrm{O} / \mathrm{C}+0.03$.

Each SOA precursor class is assigned a typical O / C value from previous investigations of marker compounds (cf. Fig A2), and results are shown in Table A1. With the knowledge of $T_{\mathrm{g}, \mathrm{org}}, k_{\mathrm{GT}}$ and $\kappa_{\mathrm{org}}$, the entire glass transition curves for the four SOA types can be calculated, as visualized in Fig. S4. Dashed lines and grey shaded areas indicate ranges of uncertainty.

\section{A5 Evaluation of the method}

For evaluation of the performance of the diffusivity estimation scheme, we compare estimated diffusivity values with values obtained in experiments by Price et al. (2014). In these experiments, $\mathrm{D}_{2} \mathrm{O}-\mathrm{H}_{2} \mathrm{O}$ exchange in an organic matrix at constant temperature and humidity is investigated by Raman spectroscopy. Figure S3 shows the experimentally determined $D_{\mathrm{H}_{2} \mathrm{O}}$ values for sucrose and levoglucosan in Price et al., (2014) (blue and red markers) as well as the $D_{\mathrm{H}_{2} \mathrm{O}}$ parameterization from Zobrist et al. (2011) (blue solid line). $D_{\mathrm{H}_{2} \mathrm{O}}$ in levoglucosan has also been estimated with the diffusivity estimation scheme (red solid line), using input parameters from Zobrist et al. (2008) $\left(T_{\mathrm{g}, \text { org }}=283.6 \mathrm{~K}, k_{\mathrm{GT}}=5.2\right)$. Water activity has been parameterized using the parameters in Table S4. Experimental and estimated values coincide for the highest and lowest water activities but differ under medium conditions due to the different curvature of the base parameterization from Zobrist et al. (2011) that underlies all calculations. However, diffusivities differ only within at most 2 orders of magnitude, which is a considerably small deviation compared to the large set of approximations made here and the difference between experimental techniques.

Figure S3 also shows the ranges of estimated diffusivity coefficients $D_{\mathrm{H}_{2} \mathrm{O}}$ for two types of $\alpha$-pinene SOA: fresh $\alpha$ pinene $\mathrm{SOA}(\mathrm{O} / \mathrm{C}=0.3$, orange dashed line $)$ and aged $\alpha$ pinene SOA $(\mathrm{O} / \mathrm{C}=0.7$, green dashed line $)$. Dark shadings confined by dotted lines indicate the range of uncertainty at a fixed $\mathrm{O} / \mathrm{C}$, corresponding to the input uncertainties used for Fig. S4. Light shadings illustrate how an uncertainty in $\mathrm{O} / \mathrm{C}$ of \pm 0.1 translates into uncertainty in $D_{\mathrm{H}_{2} \mathrm{O}}$ and thus accounts for the natural variability within SOA as complex mixture. 

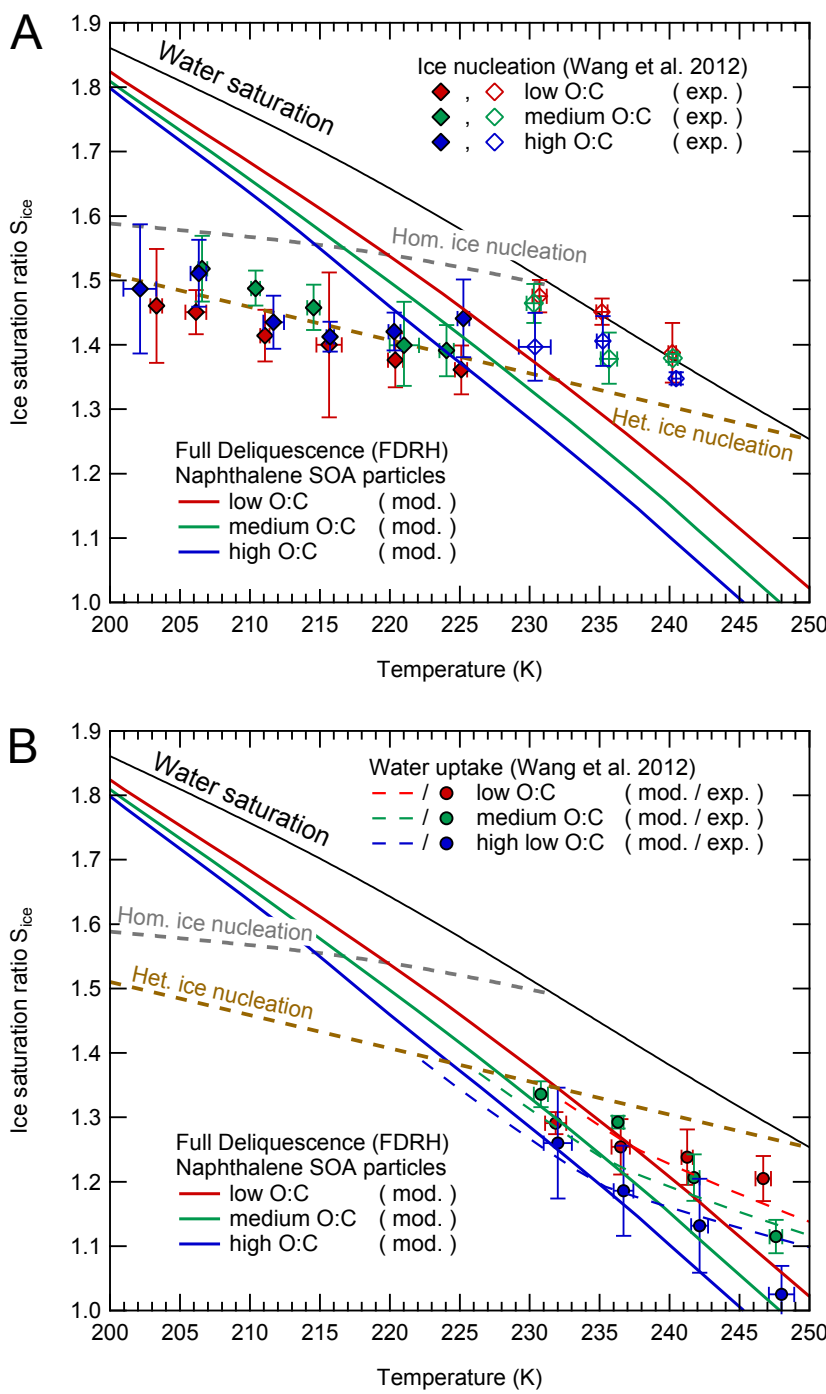

Figure B1. Comparison between calculation results of naphthalene SOA deliquescence and experimental ice nucleation and water uptake data from Wang et al. (2012). For the numerical simulations, aerosol particles are assumed to be $1 \mu \mathrm{m}$ in diameter and are humidified at a rate of $1 \% \mathrm{RH} \mathrm{min}-1$, corresponding to a cooling rate of about $0.1 \mathrm{~K} \mathrm{~min}^{-1}$ as used by Wang et al. (2012).

\section{Appendix B: Application of the model to ice nucleation experiments in the literature}

\section{B1 Sucrose experiments}

Baustian et al. (2013) investigated sucrose particles deposited on a quartz substrate and humidified inside an experimental flow cell. After cooling and drying below the glass transition, particles with an average diameter of $4 \mu \mathrm{m}$ were humidified by cooling at a rate of $0.1 \mathrm{~K} \mathrm{~min}^{-1}$. Humidification was initialized below ice saturation $\left(S_{\text {ice }}<0.9\right)$. The resulting heterogeneous ice nucleation onsets (brown circles) are shown in Fig. 2c along with the full deliquescence relative humidity

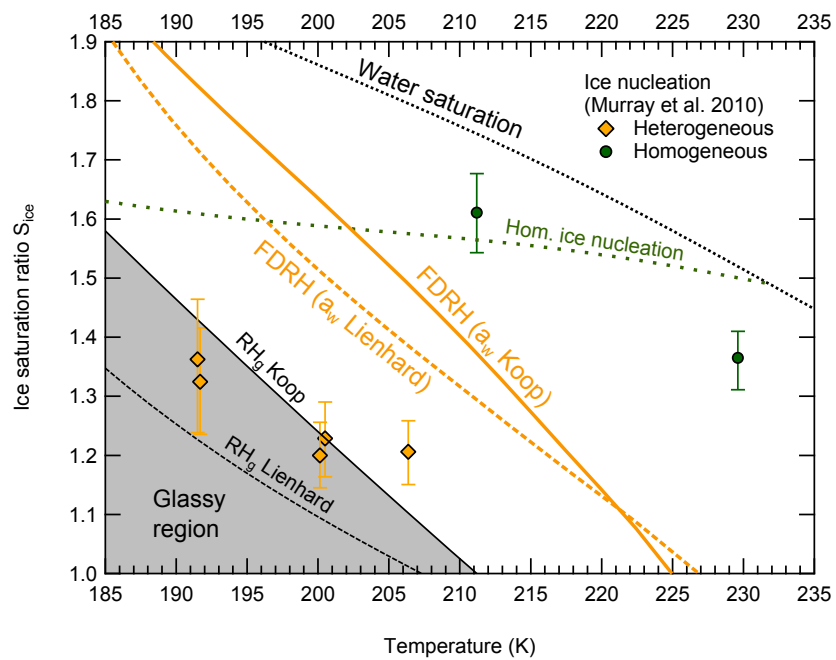

Figure B2. Comparison between calculation results of citric acid aerosol deliquescence (orange lines) and experimental ice nucleation data from Murray et al. (2010) (orange diamonds, green circles). In the numerical simulations, $150 \mathrm{~nm}$ diameter aerosol particles are humidified at a rate of $12 \% \mathrm{RH} \mathrm{min}^{-1}$, corresponding to a cooling rate of around $1-2 \mathrm{~K} \mathrm{~min}^{-1}$ typical of cloud chamber experiments. Black lines and shaded areas confine the region where a glass is the favoured thermodynamic state. The dashed lines were obtained using the water activity parameterization provided by Lienhard et al. (2012), whereas the solid lines were obtained with the parameterization in Koop et al. (2011).

(FDRH, blue solid line) from multiple model runs (spacing: $2 \mathrm{~K}$ ) mimicking the experimental conditions. Simulations below $215 \mathrm{~K}$ (left black square marker) are found to nucleate in the deposition mode, whereas particles in runs between about $215 \mathrm{~K}$ and $238 \mathrm{~K}$ (right black square marker) are assumed to undergo immersion freezing. This result is compliant with the experimental values, none of which exceeds a nucleation temperature of $235 \mathrm{~K}$. Above $238 \mathrm{~K}$ full deliquescence occurs before the ice supersaturation required for heterogeneous ice nucleation (brown dashed line) is reached. Also, homogeneous ice nucleation is not possible anymore below the water saturation limit according to Koop et al. (2000; green dashed line), leaving no remaining ice nucleation pathway.

\section{B2 Naphthalene SOA experiments}

Wang et al. (2012) generated SOA by oxidation of naphthalene by $\mathrm{OH}$ in a potential aerosol mass (PAM) reactor, deposited the particles on glass slides and investigated the onsets of water uptake and ice nucleation inside an ice nucleation cell that was mounted on a microscope. Experimental results are shown in Fig. B1 for three different SOA oxidation states: low $\mathrm{O} / \mathrm{C}(0.27)$ given in red, medium $\mathrm{O} / \mathrm{C}$ (0.54) in green and high $\mathrm{O} / \mathrm{C}(1.0)$ in blue. For the comparing model simulations, we employ our diffusivity estimation 
scheme with the glass transition parameterization for naphthalene given above. A humidification rate of $1 \% \mathrm{RH} \mathrm{min}^{-1}$ was employed and temperature varied accordingly to maintain a constant dew point. In Fig. B1, the lines of full deliquescence relative humidity (FDRH) divide the measured heterogeneous ice nucleation onsets into two groups, irrespective of the degree of oxidation used in the simulation. Heterogeneous nucleation at or below $225 \mathrm{~K}$ is consistent with simulation results (closed diamonds), whereas ice nucleation at or above $230 \mathrm{~K}$ cannot be explained with the estimated water diffusion properties (open diamonds). According to the model simulation, naphthalene SOA should be already deliquesced at temperatures and $\mathrm{RH}$ where ice nucleation is still experimentally observed. The model simulations thus suggest that solid compounds that remained in the otherwise fully deliquesced particle, possibly insoluble products from naphthalene $\mathrm{OH}$ oxidation, nucleated ice heterogeneously with lower efficiency. Such insoluble products are not considered in the model.

The reliability of the method is confirmed by comparing experimental and modelled water uptake onsets that show very good correlation. The modelled water uptake onset was defined as the point where the particle diameter had increased by $100 \mathrm{~nm}$ to take into account the fact that experimental onsets were determined by visible inspection under a light microscope.

\section{B3 Citric acid experiments}

Murray et al. (2010) observed the process of heterogeneous ice nucleation on glassy aerosol particles by investigating citric acid particles in the AIDA cloud chamber. The experimentally determined onsets of heterogeneous (orange diamonds) and homogeneous ice nucleation (green circles) are shown in Fig. B2 along with results of simulations mimicking the experimental conditions. In the calculations, we assumed a particle diameter of $150 \mathrm{~nm}$ and a humidification rate of $12 \% \mathrm{RH} \mathrm{min}-1$, corresponding to a cooling rate of $1-2 \mathrm{~K} \mathrm{~min}^{-1}$. Humidification was initiated at $S_{\text {ice }}=1$ since the cloud chamber walls were covered with ice during the initial cooling process. We performed two series of simulations for two different water activity parameterizations available in the literature. According to the parameterization in Lienhard et al. (2012) (dashed lines), heterogeneous nucleation occurs exclusively above the (equilibrium) glass transition relative humidity $\mathrm{RH}_{\mathrm{g}}$ and thus in the immersion freezing regime. With the parameterization from Koop et al. (2011) (solid lines), equilibrium glass transition and full deliquescence occur at later stages in the humidification process. According to this data, only the experimental data point at about $206 \mathrm{~K}$ would have occurred in the immersion mode.

At $212 \mathrm{~K}$, ice nucleation occurs only homogeneously in Murray's experiments, indicated by the much later ice nucleation onset. The humidification run started with liquid aerosol particles that showed retarded deliquescence, but were not able to nucleate ice heterogeneously. 


\section{The Supplement related to this article is available online at doi:10.5194/acp-14-12513-2014-supplement.}

Author contributions. T. Berkemeier, M. Shiraiwa, U. Pöschl and T. Koop designed research; T. Berkemeier, M. Shiraiwa and T. Koop developed the model; T. Berkemeier performed research; T. Berkemeier and T. Koop analysed simulation data; T. Berkemeier, M. Shiraiwa, U. Pöschl and T. Koop wrote the paper.

Acknowledgements. This work was funded by the Max Planck Society (MPG), the Deutsche Forschungsgemeinschaft through the Ice Nuclei Research Unit INUIT (FOR1525, Grant KO 2944/2-1), and the European Commission under the PEGASOS project (grant no. 265148). T. Berkemeier was supported by the Max Planck Graduate Center with the Johannes Gutenberg-Universität Mainz (MPGC). The authors thank P. Spichtinger, U. K. Krieger, D. M. Lienhard, B. P. Luo, T. Peter, A. T. Lambe, S. S. Steimer, D. A. Knopf and H.-P. Dette for stimulating discussions.

The service charges for this open access publication have been covered by the Max Planck Society.

Edited by: D. Topping

\section{References}

Adler, G., Koop, T., Haspel, C., Taraniuk, I., Moise, T., Koren, I., Heiblum, R. H., and Rudich, Y.: Formation of highly porous aerosol particles by atmospheric freeze-drying in ice clouds, P. Natl. Acad. Sci. USA, 110, 20414-20419, doi:10.1073/pnas.1317209110, 2013.

Andreae, M. O. and Rosenfeld, D.: Aerosol-cloudprecipitation interactions. Part 1. The nature and sources of cloud-active aerosols, Earth Sci. Rev., 89, 13-41, doi:10.1016/j.earscirev.2008.03.001, 2008.

Angell, C. A.: Strong and fragile liquids, in: Relaxations in Complex Systems, edited by: Ngai, K. and Wright, G. B., National Technical Information Service, I.S. Department of Commerce, Springfield, VA, 1985.

Angell, C. A.: Landscapes with megabasins: polyamorphism in liquids and biopolymers and the role of nucleation in folding and folding diseases, Physica D, 107, 122-142, doi:10.1016/s01672789(97)00077-8, 1997.

Baustian, K. J., Wise, M. E., Jensen, E. J., Schill, G. P., Freedman, M. A., and Tolbert, M. A.: State transformations and ice nucleation in amorphous (semi-)solid organic aerosol, Atmos. Chem. Phys., 13, 5615-5628, 10,

http://www.atmos-chem-phys.net/13/5615/10/.5194/acp-135615-2013, 2013.

Bones, D. L., Reid, J. P., Lienhard, D. M., and Krieger, U. K.: Comparing the mechanism of water condensation and evaporation in glassy aerosol, Proc. Natl. Acad. Sci. USA, 109, 11613-11618, doi:10.1073/pnas.1200691109, 2012.
Claeys, M., Iinuma, Y., Szmigielski, R., Surratt, J. D., Blockhuys, F., Van Alsenoy, C., Boge, O., Sierau, B., Gomez-Gonzalez, Y., Vermeylen, R., Van der Veken, P., Shahgholi, M., Chan, A. W. H., Herrmann, H., Seinfeld, J. H., and Maenhaut, W.: Terpenylic Acid and Related Compounds from the Oxidation of alpha-Pinene: Implications for New Particle Formation and Growth above Forests, Environ. Sci. Technol., 43, 6976-6982, doi:10.1021/es9007596, 2009.

Cziczo, D. J., Froyd, K. D., Hoose, C., Jensen, E. J., Diao, M. H., Zondlo, M. A., Smith, J. B., Twohy, C. H., and Murphy, D. M.: Clarifying the Dominant Sources and Mechanisms of Cirrus Cloud Formation, Science, 340, 1320-1324, doi:10.1126/science.1234145, 2013.

DeMott, P. J., Cziczo, D. J., Prenni, A. J., Murphy, D. M., Kreidenweis, S. M., Thomson, D. S., Borys, R., and Rogers, D. C.: Measurements of the concentration and composition of nuclei for cirrus formation, Proc. Natl. Acad. Sci. USA, 100, 14655-14660, doi:10.1073/pnas.2532677100, 2003.

Dette, H. P., Qi, M. A., Schroder, D. C., Godt, A., and Koop, T.: Glass-Forming Properties of 3-Methylbutane-1,2,3-tricarboxylic Acid and Its Mixtures with Water and Pinonic Acid, J. Phys. Chem. A, 118, 7024-7033, doi:10.1021/jp505910w, 2014.

Froyd, K. D., Murphy, D. M., Lawson, P., Baumgardner, D., and Herman, R. L.: Aerosols that form subvisible cirrus at the tropical tropopause, Atmos. Chem. Phys., 10, 209-218, doi:10.5194/acp10-209-2010, 2010.

Fulcher, G. S.: Analysis of recent measurements of the viscosity of glasses, J. Am. Ceram. Soc., 8, 339-355, doi:10.1111/j.11512916.1925.tb16731.x, 1925.

Gunthe, S. S., King, S. M., Rose, D., Chen, Q., Roldin, P., Farmer, D. K., Jimenez, J. L., Artaxo, P., Andreae, M. O., Martin, S. T., and Pöschl, U.: Cloud condensation nuclei in pristine tropical rainforest air of Amazonia: size-resolved measurements and modeling of atmospheric aerosol composition and CCN activity, Atmos. Chem. Phys., 9, 7551-7575, doi:10.5194/acp-9-75512009, 2009.

Hoose, C. and Möhler, O.: Heterogeneous ice nucleation on atmospheric aerosols: a review of results from laboratory experiments, Atmos. Chem. Phys., 12, 9817-9854, doi:10.5194/acp-12-98172012, 2012.

Huisman, A. J., Krieger, U. K., Zuend, A., Marcolli, C., and Peter, T.: Vapor pressures of substituted polycarboxylic acids are much lower than previously reported, Atmos. Chem. Phys., 13, 66476662, doi:10.5194/acp-13-6647-2013, 2013.

IPCC: Climate Change 2013, The Physical Science Basis, Cambridge University Press, Cambridge, United Kingdom and New York, NY, USA, 2013.

Jain, A., Yang, G., and Yalkowsky, S. H.: Estimation of melting points of organic compounds, Ind. Eng. Chem. Res., 43, 76187621, doi:10.1021/ie049378m, 2004.

Jain, A. and Yalkowsky, S. H.: Estimation of melting points of organic compounds-II, J. Pharm. Sci., 95, 2562-2618, doi:10.1002/jps.20634, 2006.

Jensen, E. J., Smith, J. B., Pfister, L., Pittman, J. V., Weinstock, E. M., Sayres, D. S., Herman, R. L., Troy, R. F., Rosenlof, K., Thompson, T. L., Fridlind, A. M., Hudson, P. K., Cziczo, D. J., Heymsfield, A. J., Schmitt, C., and Wilson, J. C.: Ice supersaturations exceeding $100 \%$ at the cold tropical tropopause: implica- 
tions for cirrus formation and dehydration, Atmos. Chem. Phys., 5, 851-862, doi:10.5194/acp-5-851-2005, 2005.

Kalberer, M., Paulsen, D., Sax, M., Steinbacher, M., Dommen, J., Prevot, A. S. H., Fisseha, R., Weingartner, E., Frankevich, V., Zenobi, R., and Baltensperger, U.: Identification of polymers as major components of atmospheric organic aerosols, Science, 303, 1659-1662, 2004.

Kautzman, K. E., Surratt, J. D., Chan, M. N., Chan, A. W. H., Hersey, S. P., Chhabra, P. S., Dalleska, N. F., Wennberg, P. O., Flagan, R. C., and Seinfeld, J. H.: Chemical Composition of Gas- and Aerosol-Phase Products from the Photooxidation of Naphthalene, J. Phys. Chem. A, 114, 913-934, doi:10.1021/jp908530s, 2010.

Kidd, C., Perraud, V., Wingen, L. M., and Finlayson-Pitts, B. J.: Integrating phase and composition of secondary organic aerosol from the ozonolysis of $\alpha$-pinene, Proc. Natl. Acad. Sci. USA, doi:10.1073/pnas.1322558111, 2014.

Knopf, D. A., Wang, B., Laskin, A., Moffet, R. C., and Gilles, M. K.: Heterogeneous nucleation of ice on anthropogenic organic particles collected in Mexico City, Geophys. Res. Lett., 37, L11803, doi:10.1029/2010gl043362, 2010.

Knopf, D. A., Alpert, P. A., Wang, B., O’Brien, R. E., Kelly, S. T., Laskin, A., Gilles, M. K., and Moffet, R. C.: Microspectroscopic imaging and characterization of individually identified ice nucleating particles from a case field study, J. Geophys. Res. Atmos., 119, JD021866, doi:10.1002/2014JD021866, 2014.

Koop, T., Luo, B. P., Tsias, A., and Peter, T.: Water activity as the determinant for homogeneous ice nucleation in aqueous solutions, Nature, 406, 611-614, doi:10.1038/35020537, 2000.

Koop, T., Bookhold, J., Shiraiwa, M., and Pöschl, U.: Glass transition and phase state of organic compounds: dependency on molecular properties and implications for secondary organic aerosols in the atmosphere, Phys. Chem. Chem. Phys., 13, 19238-19255, 2011.

Kuwata, M. and Martin, S. T.: Phase of atmospheric secondary organic material affects its reactivity, Proc. Natl. Acad. Sci. USA, 109, 17354-17359, doi:10.1073/pnas.1209071109, 2012.

Lambe, A. T., Onasch, T. B., Massoli, P., Croasdale, D. R., Wright, J. P., Ahern, A. T., Williams, L. R., Worsnop, D. R., Brune, W. H., and Davidovits, P.: Laboratory studies of the chemical composition and cloud condensation nuclei (CCN) activity of secondary organic aerosol (SOA) and oxidized primary organic aerosol (OPOA), Atmos. Chem. Phys., 11, 8913-8928, doi:10.5194/acp-11-8913-2011, 2011.

Lide, D. R.: CRC Handbook of Chemistry and Physics, CRC Press, National Institute of Standards and Technology, Boca Raton, FL, 2005.

Lienhard, D. M., Bones, D. L., Zuend, A., Krieger, U. K., Reid, J. P., and Peter, T.: Measurements of Thermodynamic and Optical Properties of Selected Aqueous Organic and Organic-Inorganic Mixtures of Atmospheric Relevance, J. Phys. Chem. A, 116, 9954-9968, doi:10.1021/jp3055872, 2012.

Lienhard, D. M., Huisman, A. J., Bones, D. L., Te, Y. F., Luo, B. P., Krieger, U. K., and Reid, J. P.: Retrieving the translational diffusion coefficient of water from experiments on single levitated aerosol droplets, Phys. Chem. Chem. Phys., 16, 16677-16683, doi:10.1039/c4cp01939c, 2014.
Marcolli, C.: Deposition nucleation viewed as homogeneous or immersion freezing in pores and cavities, Atmos. Chem. Phys., 14, 2071-2104, doi:10.5194/acp-14-2071-2014, 2014.

Mikhailov, E., Vlasenko, S., Martin, S. T., Koop, T., and Pöschl, U.: Amorphous and crystalline aerosol particles interacting with water vapor: conceptual framework and experimental evidence for restructuring, phase transitions and kinetic limitations, Atmos. Chem. Phys., 9, 9491-9522, doi:10.5194/acp-9-9491-2009, 2009.

Murray, B. J., Wilson, T. W., Dobbie, S., Cui, Z. Q., Al-Jumur, S., Mohler, O., Schnaiter, M., Wagner, R., Benz, S., Niemand, M., Saathoff, H., Ebert, V., Wagner, S., and Karcher, B.: Heterogeneous nucleation of ice particles on glassy aerosols under cirrus conditions, Nat. Geosci., 3, 233-237, doi:10.1038/ngeo817, 2010.

O'Meara, S., Booth, A. M., Barley, M. H., Topping, D., and McFiggans, G.: An assessment of vapour pressure estimation methods, Phys. Chem. Chem. Phys., 16, 19453-19469, doi:10.1039/c4cp00857j, 2014.

Perraud, V., Bruns, E. A., Ezell, M. J., Johnson, S. N., Yu, Y., Alexander, M. L., Zelenyuk, A., Imre, D., Chang, W. L., Dabdub, D., Pankow, J. F., and Finlayson-Pitts, B. J.: Nonequilibrium atmospheric secondary organic aerosol formation and growth, Proc. Natl. Acad. Sci. USA, 109, 2836-2841, doi:10.1073/pnas.1119909109, 2012.

Petters, M. D. and Kreidenweis, S. M.: A single parameter representation of hygroscopic growth and cloud condensation nucleus activity, Atmos. Chem. Phys., 7, 1961-1971, doi:10.5194/acp-71961-2007, 2007.

Price, H. C., Murray, B. J., Mattsson, J., O’Sullivan, D., Wilson, T. W., Baustian, K. J., and Benning, L. G.: Quantifying water diffusion in high-viscosity and glassy aqueous solutions using a Raman isotope tracer method, Atmos. Chem. Phys., 14, 3817 3830, doi:10.5194/acp-14-3817-2014, 2014.

Pruppacher, H. and Klett, J.: Microphysics of clouds and precipitation, 2 Edn., Kluwer Academic Publishers, Boston, MA, 1997.

Rampp, M., Buttersack, C., and Ludemann, H. D.: c,T-dependence of the viscosity and the self-diffusion coefficients in some aqueous carbohydrate solutions, Carbohyd. Res., 328, 561-572, 2000

Renbaum-Wolff, L., Grayson, J. W., Bateman, A. P., Kuwata, K., Sellier, M., Murray, B. J., Schilling, J. E., Martin, S. T., and Bertram, A. K.: Viscosity of $\alpha$-pinene secondary organic material and implications for particle growth and reactivity, Proc. Natl. Acad. Sci. USA, 110, 8014-8019, doi:10.1073/pnas.1219548110 2013.

Rickards, A. M. J., Miles, R. E. H., Davies, J. F., Marshall, F. H., and Reid, J. P.: Measurements of the Sensitivity of Aerosol Hygroscopicity and the kappa Parameter to the O / C Ratio, J. Phys. Chem. A, 117, 14120-14131, doi:10.1021/jp407991n, 2013.

Saukko, E., Lambe, A. T., Massoli, P., Koop, T., Wright, J. P., Croasdale, D. R., Pedernera, D. A., Onasch, T. B., Laaksonen, A., Davidovits, P., Worsnop, D. R., and Virtanen, A.: Humiditydependent phase state of SOA particles from biogenic and anthropogenic precursors, Atmos. Chem. Phys., 12, 7517-7529, doi:10.5194/acp-12-7517-2012, 2012.

Schill, G. P. and Tolbert, M. A.: Heterogeneous ice nucleation on phase-separated organic-sulfate particles: effect of liquid vs. glassy coatings, Atmos. Chem. Phys., 13, 4681-4695, doi:10.5194/acp-13-4681-2013, 2013. 
Schill, G. P., De Haan, D. O., and Tolbert, M. A.: Heterogeneous Ice Nucleation on Simulated Secondary Organic Aerosol, Environ. Sci. Technol., 48, 1675-1682, doi:10.1021/es4046428, 2014.

Shilling, J. E., Chen, Q., King, S. M., Rosenoern, T., Kroll, J. H., Worsnop, D. R., DeCarlo, P. F., Aiken, A. C., Sueper, D., Jimenez, J. L., and Martin, S. T.: Loading-dependent elemental composition of $\alpha$-pinene SOA particles, Atmos. Chem. Phys., 9, 771-782, doi:10.5194/acp-9-771-2009, 2009.

Shiraiwa, M., Ammann, M., Koop, T., and Pöschl, U.: Gas uptake and chemical aging of semisolid organic aerosol particles, Proc. Natl. Acad. Sci. USA, 108, 11003-11008, doi:10.1073/pnas.1103045108, 2011.

Shiraiwa, M., Pfrang, C., Koop, T., and Pöschl, U.: Kinetic multilayer model of gas-particle interactions in aerosols and clouds (KM-GAP): linking condensation, evaporation and chemical reactions of organics, oxidants and water, Atmos. Chem. Phys., 12, 2777-2794, doi:10.5194/acp-12-2777-2012, 2012.

Shiraiwa, M., Yee, L. D., Schilling, K. A., Loza, C. L., Craven, J. S., Zuend, A., Ziemann, P. J., and Seinfeld, J. H.: Size distribution dynamics reveal particle-phase chemistry in organic aerosol formation, Proc. Natl. Acad. Sci. USA, 110, 1174611750, doi:10.1073/pnas.1307501110, 2013a.

Shiraiwa, M., Zuend, A., Bertram, A. K., and Seinfeld, J. H.: Gasparticle partitioning of atmospheric aerosols: interplay of physical state, non-ideal mixing and morphology, Phys. Chem. Chem. Phys., 15, 11441-11453, doi:10.1039/C3CP51595H, 2013b.

Song, M., Marcolli, C., Krieger, U. K., Zuend, A., and Peter, T.: Liquid-liquid phase separation and morphology of internally mixed dicarboxylic acids/ammonium sulfate/water particles, Atmos. Chem. Phys., 12, 2691-2712, doi:10.5194/acp-12-26912012, 2012.

Surratt, J. D., Murphy, S. M., Kroll, J. H., Ng, N. L., Hildebrandt, L., Sorooshian, A., Szmigielski, R., Vermeylen, R., Maenhaut, W., Claeys, M., Flagan, R. C., and Seinfeld, J. H.: Chemical composition of secondary organic aerosol formed from the photooxidation of isoprene, J. Phys. Chem. A, 110, 9665-9690, doi:10.1021/jp061734m, 2006.

Szmigielski, R., Surratt, J. D., Gomez-Gonzalez, Y., Van der Veken, P., Kourtchev, I., Vermeylen, R., Blockhuys, F., Jaoui, M., Kleindienst, T. E., Lewandowski, M., Offenberg, J. H., Edney, E. O., Seinfeld, J. H., Maenhaut, W., and Claeys, M.: 3-methyl-1,2,3-butanetricarboxylic acid: An atmospheric tracer for terpene secondary organic aerosol, Geophys. Res. Lett., 34, doi:10.1029/2007g1031338, 2007.

Tammann, G. and Hesse, W.: The dependancy of viscosity on temperature in hypothermic liquids, Z. Anorg. Allg. Chem., 156, 14, 1926.

Tong, H.-J., Reid, J. P., Bones, D. L., Luo, B. P., and Krieger, U. K.: Measurements of the timescales for the mass transfer of water in glassy aerosol at low relative humidity and ambient temperature, Atmos. Chem. Phys., 11, 4739-4754, doi:10.5194/acp-11-47392011, 2011.

Vaden, T. D., Imre, D., Beranek, J., Shrivastava, M., and Zelenyuk, A.: Evaporation kinetics and phase of laboratory and ambient secondary organic aerosol, Proc. Natl. Acad. Sci. USA, 108, 2190-2195, doi:10.1073/pnas.1013391108, 2011.

Virtanen, A., Joutsensaari, J., Koop, T., Kannosto, J., YliPirilä, P., Leskinen, J., Mäkelä, J. M., Holopainen, J. K., Pöschl, U., Kulmala, M., Worsnop, D. R., and Laaksonen, A.: An amorphous solid state of biogenic secondary organic aerosol particles, Nature, 467, 824-827, doi:10.1038/nature09455, 2010.

Vogel, H.: The temperature dependence law of the viscosity of fluids, Phys. Z., 22, 645-646, 1921.

Wagner, R., Möhler, O., Saathoff, H., Schnaiter, M., Skrotzki, J., Leisner, T., Wilson, T. W., Malkin, T. L., and Murray, B. J.: Ice cloud processing of ultra-viscous/glassy aerosol particles leads to enhanced ice nucleation ability, Atmos. Chem. Phys., 12, 85898610, doi:10.5194/acp-12-8589-2012, 2012.

Wang, B. B., Lambe, A. T., Massoli, P., Onasch, T. B., Davidovits, P., Worsnop, D. R., and Knopf, D. A.: The deposition ice nucleation and immersion freezing potential of amorphous secondary organic aerosol: Pathways for ice and mixedphase cloud formation, J. Geophys. Res. Atmos., 117, D16209, doi:10.1029/2012jd018063, 2012.

Wilson, T. W., Murray, B. J., Wagner, R., Möhler, O., Saathoff, H., Schnaiter, M., Skrotzki, J., Price, H. C., Malkin, T. L., Dobbie, S., and Al-Jumur, S. M. R. K.: Glassy aerosols with a range of compositions nucleate ice heterogeneously at cirrus temperatures, Atmos. Chem. Phys., 12, 8611-8632, doi:10.5194/acp-128611-2012, 2012.

Yee, L. D., Craven, J. S., Loza, C. L., Schilling, K. A., Ng, N. L., Canagaratna, M. R., Ziemann, P. J., Flagan, R. C., and Seinfeld, J. H.: Secondary organic aerosol formation from low- $\mathrm{NO}_{x}$ photooxidation of dodecane: evolution of multigeneration gasphase chemistry and aerosol composition, J. Phys. Chem. A, 116, 6211-6230, doi:10.1021/jp211531h, 2012.

You, Y., Renbaum-Wolff, L., Carreras-Sospedra, M., Hanna, S. J., Hiranuma, N., Kamal, S., Smith, M. L., Zhang, X. L., Weber, R. J., Shilling, J. E., Dabdub, D., Martin, S. T., and Bertram, A. K.: Images reveal that atmospheric particles can undergo liquid-liquid phase separations, Proc. Natl. Acad. Sci. USA, 109, 13188-13193, doi:10.1073/pnas.1206414109, 2012.

You, Y., Smith, M. L., Song, M. J., Martin, S. T., and Bertram, A. K.: Liquid-liquid phase separation in atmospherically relevant particles consisting of organic species and inorganic salts, Int. Rev. Phys. Chem., 33, 43-77, doi:10.1080/0144235x.2014.890786, 2014.

Yu, H., Kaufman, Y. J., Chin, M., Feingold, G., Remer, L. A., Anderson, T. L., Balkanski, Y., Bellouin, N., Boucher, O., Christopher, S., DeCola, P., Kahn, R., Koch, D., Loeb, N., Reddy, M. S., Schulz, M., Takemura, T., and Zhou, M.: A review of measurement-based assessments of the aerosol direct radiative effect and forcing, Atmos. Chem. Phys., 6, 613-666, doi:10.5194/acp-6-613-2006, 2006.

Zhang, X., Schwantes, R. H., Coggon, M. M., Loza, C. L., Schilling, K. A., Flagan, R. C., and Seinfeld, J. H.: Role of ozone in SOA formation from alkane photooxidation, Atmos. Chem. Phys., 14, 1733-1753, doi:10.5194/acp-14-1733-2014, 2014.

Zhou, S., Shiraiwa, M., McWhinney, R., Pöschl, U., and Abbatt, J. P. D.: Kinetic limitations in gas-particle reactions arising from slow diffusion in secondary organic aerosol, Faraday Discuss., 165, 391-406, doi:10.1039/C3FD00030C, 2013.

Zobrist, B., Weers, U., and Koop, T.: Ice nucleation in aqueous solutions of poly ethylene glycol with different molar mass, J. Chem. Phys., 118, 10254-10261, doi:10.1063/1.1571818, 2003.

Zobrist, B., Marcolli, C., Pedernera, D. A., and Koop, T.: Do atmospheric aerosols form glasses?, Atmos. Chem. Phys., 8, 52215244, doi:10.5194/acp-8-5221-2008, 2008. 
Zobrist, B., Soonsin, V., Luo, B. P., Krieger, U. K., Marcolli, C., Peter, T., and Koop, T.: Ultra-slow water diffusion in aqueous sucrose glasses, Phys. Chem. Chem. Phys., 13, 3514-3526, doi:10.1039/c0cp01273d, 2011.
Zuend, A. and Seinfeld, J. H.: Modeling the gas-particle partitioning of secondary organic aerosol: the importance of liquidliquid phase separation, Atmos. Chem. Phys., 12, 3857-3882, doi:10.5194/acp-12-3857-2012, 2012. 